\title{
Discussion of Thermal Experiments' Capability to Screen the Feasibility of Air Injection
}

Siyuan Huang ${ }^{\mathrm{a}}$, James J. Sheng ${ }^{\mathrm{a}, \mathrm{b}_{*}}$

a Texas Tech University. b Southwest Petroleum University

* Corresponding author. Tel.: +1 806834 8477; E-mail: james.sheng@ @tu.edu

Keywords: Air injection; Thermal experiments; Screening criteria; Kinetic study

\begin{abstract}
Thermal experiments such as thermogravimetric analysis (TGA), differential scanning calorimetry (DSC), accelerating rate calorimetry (ARC), and small batch reactor (SBR) are typically used to screen the feasibility of air injection in a reservoir. In this paper, the capability of these tools were studied. The screening criteria for air injection process (AIP) based on the thermal experiments were summarized. A practical workflow to use the thermal experiments to build a base simulation model for AIP it was proposed. In an AIP simulation model, there are about 12 variables to govern the process. Generally, researchers consider kinetic data as adjustable variables to match experimental or field data. How to properly adjust the kinetic data and understand the effect of the kinetic data on the production performance of a reservoir are not well established. In this paper, the reaction temperature ranges and the exothermic peak temperatures for the low temperature oxidation (LTO) stage and high temperature oxidation (HTO) stage were summarized from the experiments using 19 crude oils. The measured kinetic data of 22 different crude oils, and the kinetic data of 25 sets of crude oils with the presence of additives were also summarized. From these data, the ranges of activation energy and frequency factor were defined as the reference for future studies, if such data are readily available. A simulation study has been conducted to study the significance of the kinetic data on production performance. It is observed that the variation of the activation energy significantly influence the recovery performance while the variation of the frequency factor does not.
\end{abstract}

\section{Introduction}

AIP (air injection process) is one of EOR methods. For a heavy oil reservoir, the ISC (in-situ combustion) is usually considered, and for a light oil reservoir, the HPAI (high pressure air injection) is usually considered. The differences between conventional reservoir engineering and 
combustion reservoir engineering has been discussed by Gutierrez et al. [1]. One reason for the differences is the complicated reaction mechanisms among crude oil, rock, and air.

Similar to other EOR techniques, feasibility tests including both numerical simulation studies and laboratory studies have to be considered before conducting a field test. In order to reliably predict the field performance through the numerical simulation, both a well understood kinetic model and a fluid model are required. A well-established kinetic model contains a series of relevant reactions of the oil, rock, and air, and this is also why the chemical reactions between air and oil-rock system are so important for an AIP project. In order to create a kinetic model for the AIP, the thermal-oxidative feature of the oil and rock system of a specific reservoir need to be understood. To do that, different experimental techniques have been utilized during the last few decades. There are two categories of experimental studies for the AIP: qualitative studies and quantitative studies. The quantitative study is known as the combustion tube test, which is not the focus of this paper. Thins study mainly talks about the role of the qualitative study, which is also called the "Screening" or "Fingerprinting" study. Thermal experiments such as TGA (thermogravimetric analysis), DSC (differential scanning calorimetry), DTA (differential thermal analyzer), ARC (accelerating rate calorimetry), SBR (small batch reactor) etc., belong to qualitative studies.

The intention of these screening studies was to evaluate the potential of the reservoir for AIP implementation. However, it has been found that the established screening criteria may have to use the reservoir properties and production history to evaluate the reservoir [2, 3]. Questions such as "How do we use the thermal experiments to guide the selection of candidate reservoir for the AIP" and "What is the role of the thermal experiments in an AIP" are not well answered. Therefore, it is necessary to study the role of those screening techniques to guide the design of an AIP project.

This paper first reviews the attempts using screening tools for a feasibility study and summarize the screening criteria for the AIP base on the implementation of the thermal experiments. Then a practical workflow which uses the thermal experiments to build the base model for the further AIP simulation study was proposed. After that, the kinetic data of 22 crude oils and 25 crude oils with the presence of additives were summarized, and a general range of the kinetic data for researchers to tune their model or to set up their model were provided. Finally, a simulation 
study was conducted, and the effect of the kinetic data on reservoir recovery performance is analyzed.

\section{Overview of thermal experiments' functions}

Over the last decades, thermal experiments have been applied to investigate the combustion reactions during the AIP. As mentioned previously, despite of the convention combustion tube tests, various thermal experiments were conducted to study the air injection process. This section briefly introduces the functions of the thermal experiments in the air injection study.

DTA and DSC are used to measure the thermal behavior of the crude oil through the experiment. During the experiment, the crude oil is heated at a constant heating rate with the presence of the continuous air flow. From the thermograms, information such as temperature intervals of different oxidation reaction stages and exothermic peaks are extracted and interpreted. Generally, there will be two exothermic peaks shown in the thermograms, which are signaled by the onset of LTO (low temperature oxidation) and HTO (high temperature oxidation), respectively. Identifying the exothermic peaks actually tells us at what temperature the oxidation reactions can be triggered, which helps determine the ignition condition. On the other hand, the relevant kinetic data such as frequency factor and activation energy can be obtained through analyzing the thermograms. TGA is used to measure the mass change of the crude oil through the experiment. Similar to the DTA and the DSC, during the TGA experiment, a sample is heated at a constant heating rate with the presence of the continuous air flow. In most of the cases, there will be two sudden mass losses of the crude oil present in the TGA thermograms. These losses indicate the LTO and the HTO. Between the LTO and HTO, there is a stage where the mass loss rate stays relatively unchanged, which indicates the FD (fuel deposition) stage. The relevant kinetic data such as activation energy and frequency factor can also be estimated through analyzing the thermograms of the TGA. ARC is used to detect the self-heat rate of the crude oil, and it can maintain nearly perfect adiabatic conditions through the test. During the test, once the self-heat rate is detected, the time, temperature, and pressure data are recorded. Then, the thermal data and kinetic data can be derived. The advantage of the ARC is that it can be applied at a very high pressure condition (till $6000 \mathrm{psi}$ ). A SBR has two sample holders, one is the reactor and the other is served as the reference cell. The reactor is subjected to a heating schedule while air is flown through. The heating is continued at the desired rate until the termination is reached and then 
held at that temperature during the test of the test. During the test, the temperature profiles of both reactor and reference cell are measured. By comparing these two profiles, the temperature intervals of the exothermic and the endothermic process can be identified. Relevant kinetic data can also be estimated through analyzing SBR data.

\section{Attempts to use thermal experiments in the feasibility study}

Constant attempts were made by researchers to conduct an AIP feasibility study using thermal experiments. The objective of these attempts was to screen better reservoir candidates for field AIP implementation. The traditional experiment used for this purpose is known as the combustion tube test; however, this test cannot provide any kinetic data for the combustion reactions. Also, when compared to screening tools, the cost and time spent in conducting a combustion tube test is much higher. Tadema [4] first proposed that instead of using conventional combustion tube tests to evaluate the combustion reactions, we might use quicker and more cost-effective DTA and TGA (thermogravimetric analysis) tools. Later, Bae [5] used the DTA to study various crude oils, with gravity ranging from $6^{\circ}$ to $38^{\circ} \mathrm{API}$. The result shows that the API gravity of the oils have no obvious relation to their thermo-oxidative behaviors. Bae mentioned that when the pressure was at $1000 \mathrm{psig}$, the oil which could generate more heat in the LTO than the HTO stage from the DTA experiments could be considered as a good candidate for AIP. This is because when the crude oil shows highly reactive behavior in the LTO stage, more heat could be used to sustain the combustion front. Although he did not systematically discuss how to use the thermal experiments to screen the crude oils for AIP, he has mentioned about the screening function of the thermograms.

Attempts to use thermal experiments for AIP screening were made by Vossoughi et al. [6]. A kinetic model of the combustion reaction was built from TGA/DSC. They used TGA/DSC experiments to provide these parameters: minimum front temperature, minimum crude oil saturation, average $\mathrm{H} / \mathrm{C}$ atomic ratio, minimum amount of fuel lay-down, minimum heat requirement, combustion zone thickness, average carbon combustion rate, combustion front velocity, average fuel heat value, heat available to sand, average combustion peak temperature which used to be provided by combustion tube tests. The estimated results have been compared with results from the combustion tube, and the results agreed except for those parameters associated with the heat of reaction. The heat value estimated from the TGA/DSC is significantly 
lower than the value from the combustion tube test, and the reason is due to lack of the fluid flow and displacement behavior associated with DSC. This attempt also indicates that the combustion tube test cannot be replaced by those thermal experiments due to the lack of fluid flow and displacement behavior. After realizing the limitation of TGA/DSC, Kharrat et al. [7] built a new ISC feasibility study workflow by using the TGA/DSC. In this study, minimum crude oil content $\mathrm{W}_{\min }$ is compared with the reservoir crude oil content $\mathrm{W}_{\mathrm{R}}$, and if $\mathrm{W}_{\min }$ is higher than the $\mathrm{W}_{\mathrm{R}}$, then this reservoir is considered to be the candidate reservoir for ISC. The $\mathrm{W}_{\min }$ is calculated by using the required minimum front temperature (which is obtained from the TGA) minus the room temperature, and the heat value of crude (which is obtained from the DSC). Corresponding combustion tube tests have also been conducted, which show consistent results with this predicted workflow. From this study, it is seen that the purpose of the TGA/DSC is actually to screen the prospective crude oil/cutting system for the combustion tube tests. In other words, this study transforms the role of TGA/DSC into screening tests which are conducted prior to the combustion tube tests. As mentioned before, the cost of a combustion tube test compared to a TGA/DSC test is enormous. In addition, the combustion tube cannot provide kinetic data. This workflow can serve as a precursory experimental work prior to combustion tube tests.

Another ISC feasibility study was proposed by Yannimaras et al. [8] which is similar to the feasibility study proposed by Kharrat et al. In their work, instead of using TGA/DSC, Yannimaras et al. used the ARC to conduct the feasibility test. They claimed it was inadequate to only be given a minimum oil content to screen the candidate crude oil for AIP, and stated that the ARC is a better technique for the screening process. They compared two ARC cases, the one which is classified as an unsuitable oil for ISC shows an exothermic temperature range ending at around $250{ }^{\circ} \mathrm{C}$; the other, which is considered to be an ISC suited oil, presented continuous exothermic activity until $380{ }^{\circ} \mathrm{C}$. This temperature is believed to be high enough to sustain the combustion front. After the ARC tests, they also conducted corresponding combustion tube tests to prove their prediction, and the results agree with their hypothesis. This study pointed out that besides only considering the minimum oil content, it is also important to analyze the continuous exothermic activity between ignition temperature and the combustion front temperature of the crude oil. However, this method is still a precursory screening step to the combustion tube test, instead of replacing it. Similar tests have been done by Fraim et al. [9]. Six ARC tests and five combustion tube tests were made in order to screen the air injection project in a waterflooded 
North Sea oil reservoir. In their test, the role of ARC tests was also to determine whether the exothermic behavior is continuous or not. However, the difference between the study by Fraim et al. and that by Yannimaras et al. is that their expected exothermic temperature ranges were different. Instead of requiring the exothermic activity to continue from the reservoir temperature to $380{ }^{\circ} \mathrm{C}$, they claimed the exothermic behavior should last to $500{ }^{\circ} \mathrm{C}$. They stated that if the exothermic activity reaches $500{ }^{\circ} \mathrm{C}$, the HTO mode will occur, which produces the highest carbon dioxide percentage. However, they did not discuss how to define the required exothermic temperature interval, and whether the maximum exothermic temperature should be used to sustain the combustion front or to trigger the HTO mode.

Sarma et al. [10] conducted both ARC and TGA/PDSC (pressurized DSC) experiments to rank three oils for combustion tube tests. Oils A, B, and C were analyzed through ARC and TGA/PDSC tests. In their study, the primary screening tool is ARC which provides information such as ignition temperature, exothermic temperature range, and activation energy. The TGA/PDSC were used as supplemental tools, which helps identify the reaction mechanism of crude oils. They recognized that the purpose of ARC and TGA/PDSC tests is to rank the crude oil for subsequent combustion tube tests rather than directly provide an answer to the feasibility test. Their method ranked the oil mainly based upon the results from ARC tests. Based on their results, the oil which has a lower activation energy is a better candidate for ISC; the oil which has a lower ignition temperature is more promising for ISC; the oil which has a longer and more stable exothermic activity zone is a better candidate for ISC; the oil which can quickly achieve the ignition temperature is a better candidate for ISC.

Other than what have been summarized above, many attempts have been made to study the feasibility of AIP by various thermal experiments other than combustion tube tests. However, most of these studies only qualitatively evaluated the possible potential of an oil and rock system for conducting an AIP. TGA and DSC have been employed by many researchers to identify the oxidation reaction scheme and examine the thermal-oxidative behavior of different crude oils and oil-rock mixture samples [11-19]. Although, these studies do not provide quantitative results, the information could still be interpreted in order to help predict the candidate oil samples for further combustion tube tests. Al-Saffar et al. [20] used a high pressure oxidation cell to study the oxidation behavior of a North Sea light oil. High oxygen utilization and corresponding flue 
gas generation were observed at low temperature stages. This phenomenon has been viewed as a desirable characteristic for AIP, because a high level of flue production at low temperatures can increase oil displacement and has no negative effect on the oil properties. Hou et al. [21] used the SBR to study the oxidative feature of Xinjiang crude oils. The thermograms of the SBR show that the initial reaction rate at the reservoir temperature is relatively high, which indicates that thermal effects produced from the LTO stage can be more easily achieved in this reservoir. Juan et al. [22] used ARC and combustion tube tests to screen potential candidate reservoirs in two waterflooded light oil reservoirs. ARC tests were employed to provide kinetic data and detect the reactive and non-reactive temperature intervals. Abrupt temperature increases were detected around $230{ }^{\circ} \mathrm{C}-240{ }^{\circ} \mathrm{C}$ for both oils, and this strong reaction in the low temperature range shows a favorable indication for subsequent combustion tube tests.

Based on the review above, the screening criteria can be built from the thermal experiments which is summarized below.

1) The minimum crude oil content $W_{\text {min }}$ must be higher than the reservoir crude oil content $\mathrm{W}_{\mathrm{R}} \cdot[7]$

2) The crude oil should exhibit a continuous exothermic activity between ignition temperature and the combustion front temperature. [8]

3) If the previous two criteria are satisfied, below are some methods to rank the oil.

- The oil which has a lower activation energy is better for AIP; [10]

- The oil which has a lower ignition temperature is more promising for AIP; [10]

- The oil which has a longer and more stable exothermic activity zone is better for AIP; [10]

- The oil which has a higher oxygen utilization and a stronger flue gas generation at the LTO is better for AIP; [20-22]

\section{Role of the thermal experiments in the workflow for air injection modeling}

It is acknowledged that a field scale simulation model can provide useful forecast to the field project. Although the field scale AIP simulation modeling has not been well established, the ultimate goal when building the AIP simulation model is to have a good predictability. A detailed work flow to build an AIP simulation model has been introduced by Gutierrez et al. [23]. 
In this paper, a practical workflow was proposed which focuses on the utilization of the thermal experiments in the air injection modeling. Similar to the previous section that the thermal experiment is served as the precursory experimental work prior to combustion tube tests. This workflow described how to use the thermal experiments to build a base simulation model before using the combustion tube tests to tune it. The workflow presented here is based on the method of Guitirrez et al. [23]. The workflow is an iterative process which generally starts with defining the pseudo components to represent the oil composition. It is important that the pseudo components should represent the oil in both physical and chemical aspects. The physical aspect includes the physical properties of the crude oil such as molecular weight, critical pressure, and critical temperature. The chemical aspect includes the thermo-oxidative behavior of the crude oil during an AIP. The thermo-oxidative behavior of crude oil is mainly controlled by the kinetic model which includes reaction scheme, enthalpy from the reactions, activation energy, and frequency factor etc.

After defined the pseudo components, build the fluid model and the kinetic model are the next step. Since most of the thermal experiments are lack of the fluid flow process. The fluid model can be simply built by applying the thermal simulators to estimate the phase behavior of the crude oil during the AIP process. For example, use the CMG-Winprop to calculate the K-Value tables to estimate the phase behavior of the crude oil during the simulation.

To build the kinetic model, it is necessary to first interpret the thermograms of the thermal experiments. Based on the interpretation of the thermograms, the dominant reaction in each specific temperature region can be defined. The reaction scheme can then be proposed based on the most relevant reaction mechanisms [1] and the pseudo components defined from the previous stage. In order to validate the kinetic model, the reaction scheme and other relevant kinetic data in the simulation model are adjusted within a reasonable range to match the thermo-oxidative behavior of the crude oil. The kinetic data estimated from the thermal experiments are matched with the kinetic data derived from the simulation model. If the match is not successful, the above processes to define pseudo components, to build fluid model and to define kinetic model need to be repeated. After the kinetic model and the fluid model been calibrated with the thermal experimental data, the base model is built and can be used in a further combustion tube tuning process. 
Some of the practices which have used the thermal experiments to build the base simulation model are listed in this paragraph. Battarcharya et al. [24] developed the numerical model based on the ARC experiments. Khansari et al. [25] proposed the reaction scheme based on the analysis of the TGA experiments. Dechelette et al. [26] matched the ramped temperature experiments with CMG and proposed the improved reaction scheme.

In summary, the role of the thermal experiments in the air injection modeling is to build the base model for the further simulation study. Some of the examples are to determine the temperature ranges for LTO and HTO; to estimate the kinetic data from the thermal experiments and the sensitivity test of the experimental parameters are further reviewed in the next sections.

\section{Define temperature regions for LTO and HTO by using thermal experiments}

Generally, there are three reactions during the air injection process as: LTO, FD, and HTO. Based on the interpretation of the thermograms, temperature regions of each reaction stage can be determined. Since the kinetic data is estimated for different reaction stages, respectively. Defining the reaction temperature regions need to be done prior than estimation of the kinetic data. Also, based on the reaction temperature regions, researchers are able to predict what type of reactions could occur during the AIP and whether they are achievable. In this section, 19 crude oils' reaction temperature regions were summarized as shown in Fig. 1 [6, 10-12, 16, 17, 27-31]. It is observed that the API gravity of the oil does not show a direct relation to the reaction temperature regions. Based on the data in Fig. 1, the "average reaction temperature regions" for LTO and HTO were estimated as: $149 \sim 364{ }^{\circ} \mathrm{C}$ for the LTO and $415 \sim 542{ }^{\circ} \mathrm{C}$ for the HTO.

Thermal experiments as DTA, DSC and ARC can present the exothermic and endothermic behavior of the crude oil during the experiments. The sharpest and highest exothermic region in the exothermic region are named as exothermic peaks, which indicate the potential combustion of the crude oil. Generally, there are two exothermic peaks. One locates in the low temperature region which corresponds to the LTO. The other exothermic peak locates at the high temperature region which indicates corresponds to the HTO. The first peak was considered as liquid hydrocarbons combustion and the second peak was considered as coke combustion [27]. Generally, the second exothermic peak has a much stronger heat generation than the first peak, which is also the main source for the spontaneous ignition. Fig. 2 shows 12 crude oils' 
exothermic peaks temperature in low temperature region and high temperature region, respectively $[10-12,16,17,27-30]$. The exothermic peaks can help researchers to understand the spontaneous ignition potential of the crude oil. The lower temperature of the exothermic peak indicates it is easier to ignite the oil. Therefore, exothermic peaks can be considered as one aspect to screen the candidate oil for the AIP. Based on the data summarized in Fig. 2, the average combustion peak temperature are $320^{\circ} \mathrm{C}$ in the LTO stage and $469{ }^{\circ} \mathrm{C}$ in the HTO stage. 


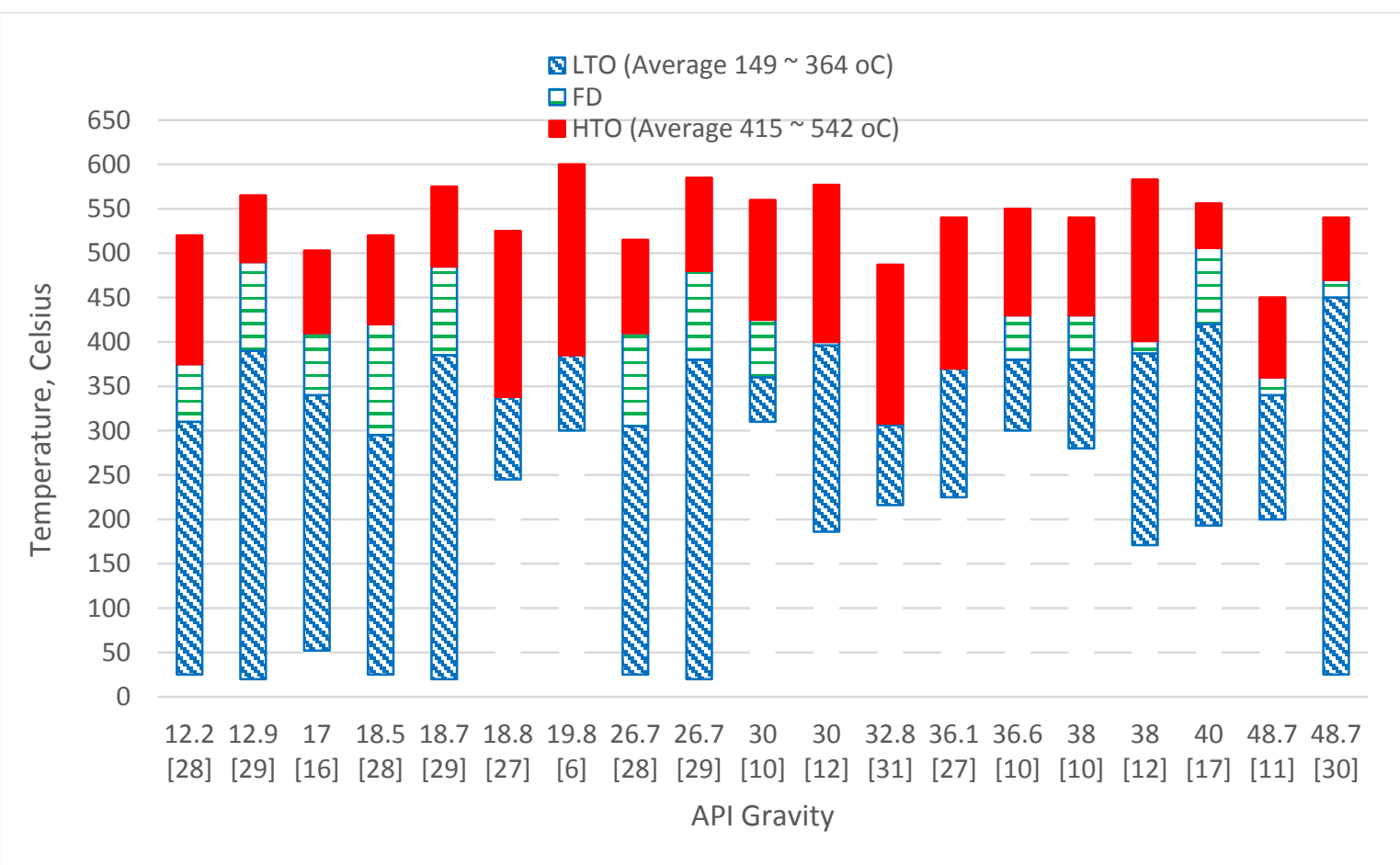

Figure 1, LTO, FD and HTO temperature regions for 19 crude oils

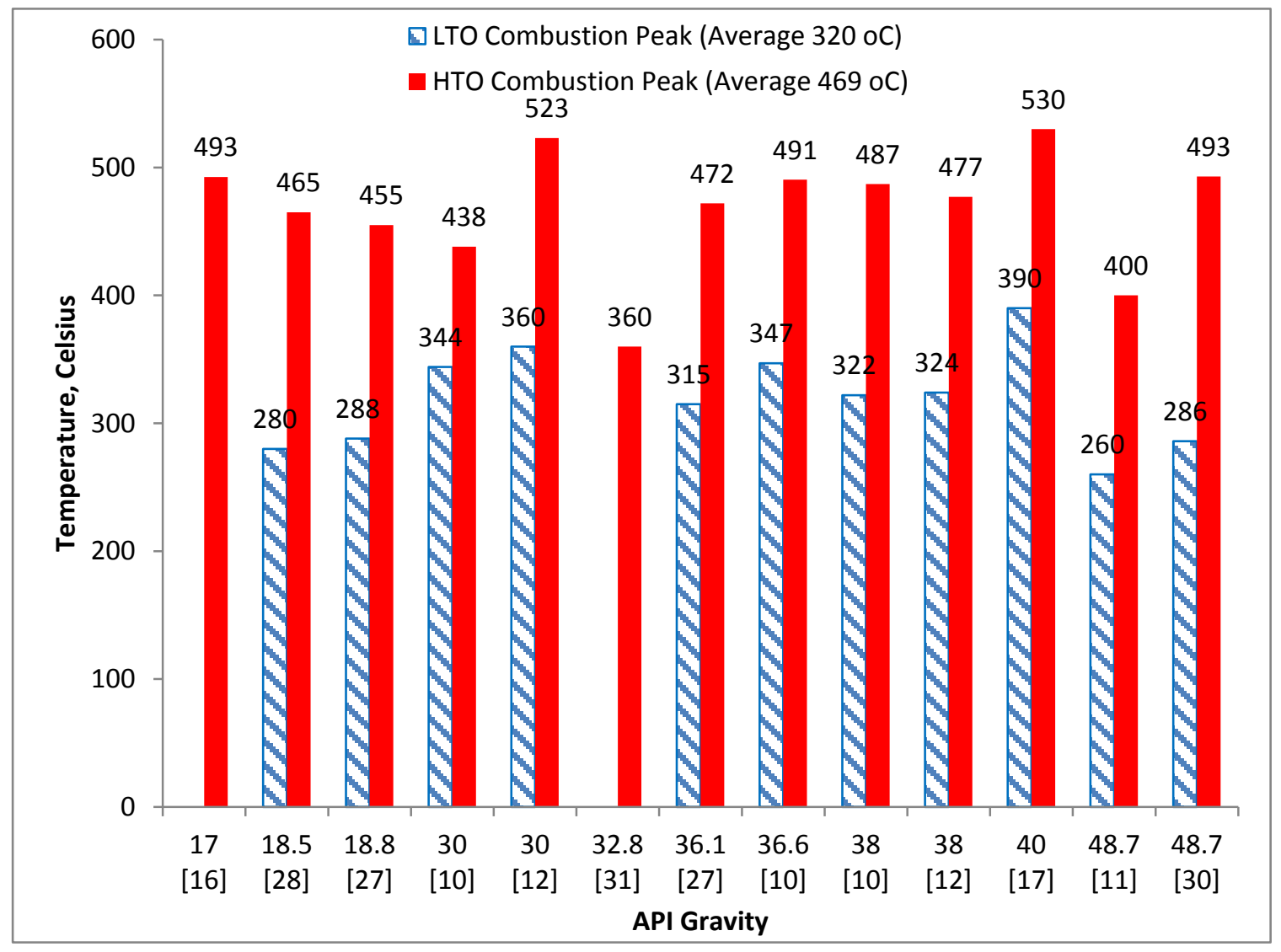

Figure 2, LTO and HTO combustion peaks of 13 crude oils 


\section{Kinetic study of crude oil by using thermal experiments}

As mentioned before, in order to build the numerical simulation model for the AIP, kinetic model which consists of the relevant kinetic data is required. Thermal experiments as TGA, DSC, ARC, and SBR are often utilized to establish kinetic data as Ea (activation energy), Ar (frequency factor) and order of the reaction for kinetic model. In most of the studies, the Arrhenius method is employed to derive the kinetic data. According to the Arrhenius model [32], the temperature-dependent rate constant $\mathrm{k}(\mathrm{T})$ can be specified as:

$k(T)=\operatorname{Arexp}\left(-\frac{E a}{R T}\right)$

where $\mathrm{Ar}$ is the frequency factor $\left(\mathrm{s}^{-1}\right), \mathrm{Ea}$ is the activation energy $\left(\mathrm{KJ} \mathrm{mol}^{-1}\right), \mathrm{T}$ is the temperature $(\mathrm{K})$, and $\mathrm{R}$ is the universal gas constant. After obtained the thermograms from the thermal experiments and defined the reaction temperature regions, kinetic data in each reaction stage can be estimated by analyzing the thermograms with different kinetic analysis methods.

Activation energy is the most frequently reported kinetic data which is often used for characterizing the reactivity of the crude oil, to qualitatively determine the conditions required to achieve ignition, and to determine if self-ignition will take place in the reservoir upon air injection. If the activation energy of a reaction scheme is lower, the reaction can be triggered more easily, or the reaction can be more readily sustained. In this paper, the kinetic data as activation energy in LTO and HTO are summarized separately, from 22 different crude oils, and with API gravity ranges from 11 to 44.3 [9, 14, 17, 20, 28, 30, 33, 35-43]. No relation between the API gravity and the activation energies were found based upon the data, which implies that the API gravity of the crude oil cannot be used as an all-descriptive measure of the thermal behavior of crude oil [5]. Fig. 3 shows the distribution of the kinetic data of these crude oils. It is observed that in the medium range, $20 \sim 80 \%$ of oils have activation energies in the LTO stage from $20 \sim 70 \mathrm{KJ} / \mathrm{mol}$, and $50 \%$ of the oil has $33 \mathrm{KJ} / \mathrm{mol} \mathrm{Ea}$ in the LTO stage. It is also observed that $20 \sim 80 \%$ of oils in the medium range have activation energies in the HTO stage from $70 \sim$ $180 \mathrm{KJ} / \mathrm{mol}$, and $50 \%$ of the oil has $107 \mathrm{KJ} / \mathrm{mol} \mathrm{Ea}$ in the HTO stage.

The frequency factor data from 11 different crude oils were also summarized as shown in Fig 4 $[10,17,28,30,34,39-41]$. It is observed that the API gravity of the crude oil does not have a relation to the frequency factor values. Also, it is observed that the value of the frequency factor 
in the LTO $\left(0.1 \sim 10^{5} \mathrm{~s}^{-1}\right)$ are generally lower than the frequency factor in the HTO $\left(10^{4} \sim 10^{9} \mathrm{~s}^{-}\right.$ ${ }^{1}$ ). The huge difference among the frequency factor values might be caused by the fact that Ar is obtained as the intercept on the log axis which is very sensitive to the slope selected by the researchers. In other words, a very small change in the slop could cause a large difference in Ar.

With the above Ea and Ar values, the rate constants can be calculated by using Equation 1. The rate constant curves in the LTO stage and the HTO stage for different crude oils are displaced in Fig 5 and Fig 6, respectively. The temperature ranges are selected as $25-350{ }^{\circ} \mathrm{C}$ for the LTO and 350-600 ${ }^{\circ} \mathrm{C}$ for the HTO [28]. Two "average reaction rate curves" were drawn in Fig 5 and Fig 6, which can be served as reference curves for researchers to compare their data. It is observed that the rate constant increases with temperature, and the value of the rate constant for different crude oils vary from $10^{-13} \sim 10^{2} \mathrm{~s}^{-1}$ in the LTO stage, and $10^{-9} \sim 10^{2} \mathrm{~s}^{-1}$ in the HTO stage. Fig 5 and Fig 6 again indicate that the value of the kinetic data has no direct relation to the API gravity of the crude oil.

Based on this section, a general range of kinetic data was provided for researchers to tune their model or as the starting point to set up their model. The activation energy in HTO $(107 \mathrm{KJ} / \mathrm{mol})$ should be higher than the activation energy in the LTO $(33 \mathrm{KJ} / \mathrm{mol})$. And a general range of activation energy is more likely to fall in $20 \sim 70 \mathrm{KJ} / \mathrm{mol}$ in the LTO and $70 \sim 180 \mathrm{KJ} / \mathrm{mol}$ in the HTO. The frequency factor range of the crude oil in LTO is $0.1 \mathrm{~s}^{-1}$ to $10^{5} \mathrm{~s}^{-1}$, and $10^{4} \mathrm{~s}^{-1}$ to $10^{9} \mathrm{~s}^{-1}$ in the HTO.

Since many variables in a numerical model need to be estimated from both thermal experiments and combustion tube experiments, most of the time, the Ea and the Ar values are adjusted [1]. More importantly, in a practical simulation model, researchers define a reaction scheme of several reactions for a single reaction state (e.g., HTO), then several sets of kinetic data are needed to define HTO reactions. Thus a single set of kinetic data for HTO may not serve the need in simulation, although thermal experiments are conducted to measure these data. This discussion reveals that the conventional analysis of thermal experimental data to obtain a single set of kinetic data based on Equation 1 may not be practically very useful. Khansari et al. [44] have provided a series of kinetic data based on the reaction products for the LTO stage, which makes the kinetic model more adequate for modeling the LTO process. 


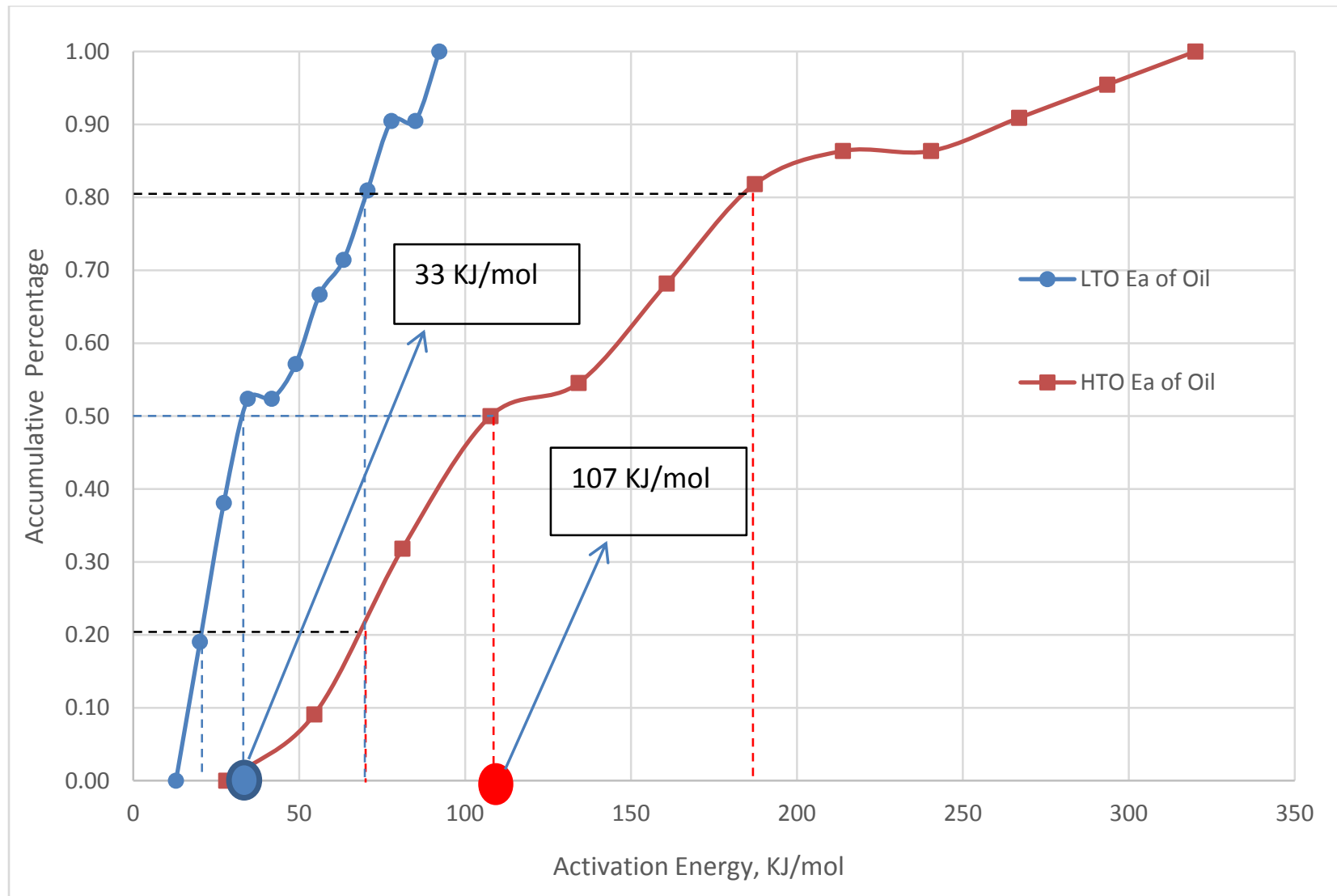

Figure 3, Activation energy (Ea) of 22 crude oil samples in LTO and HTO, respectively 


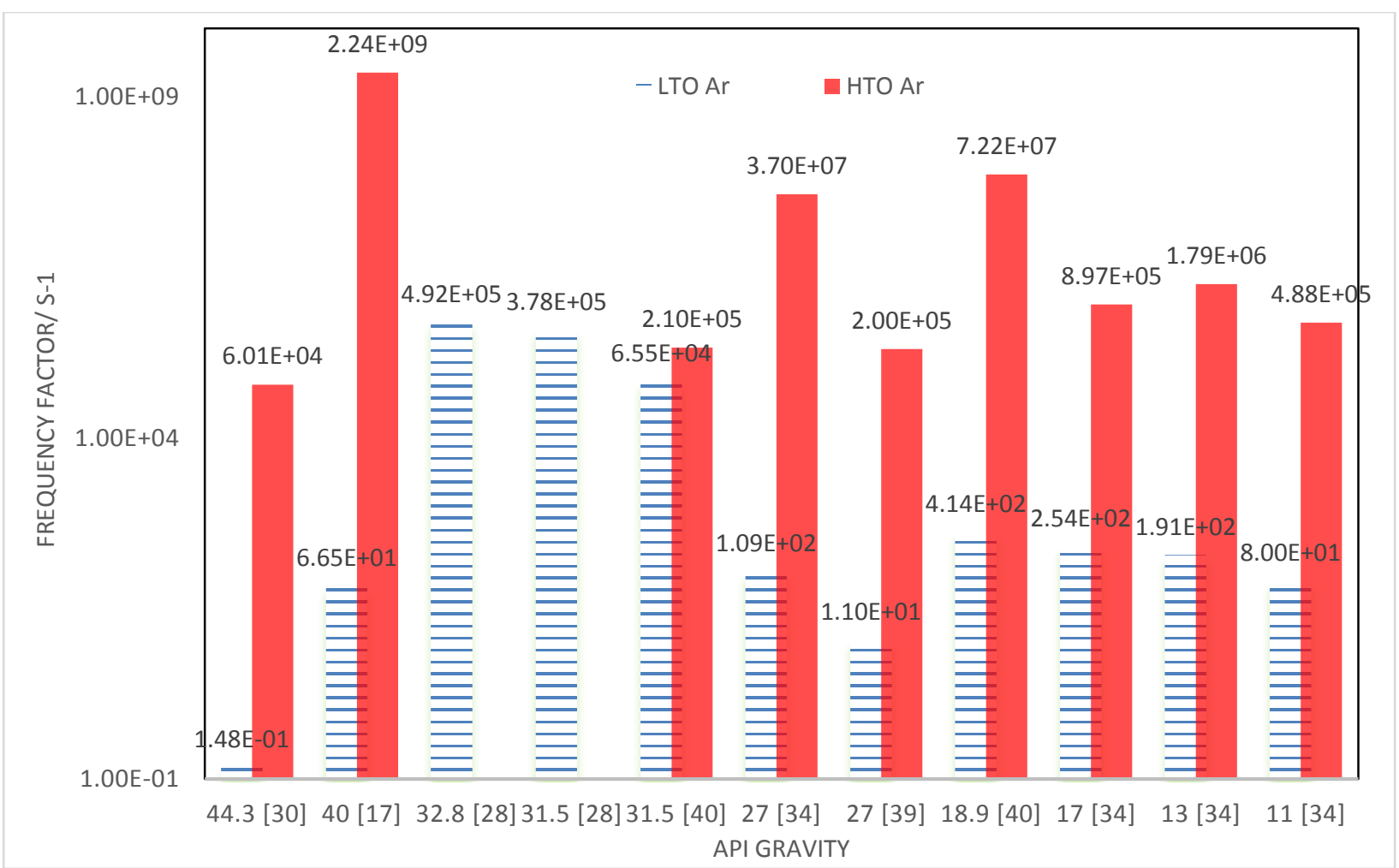

Figure 4, Frequency factor (Ar) of 11 crude oil samples in LTO and HTO respectively

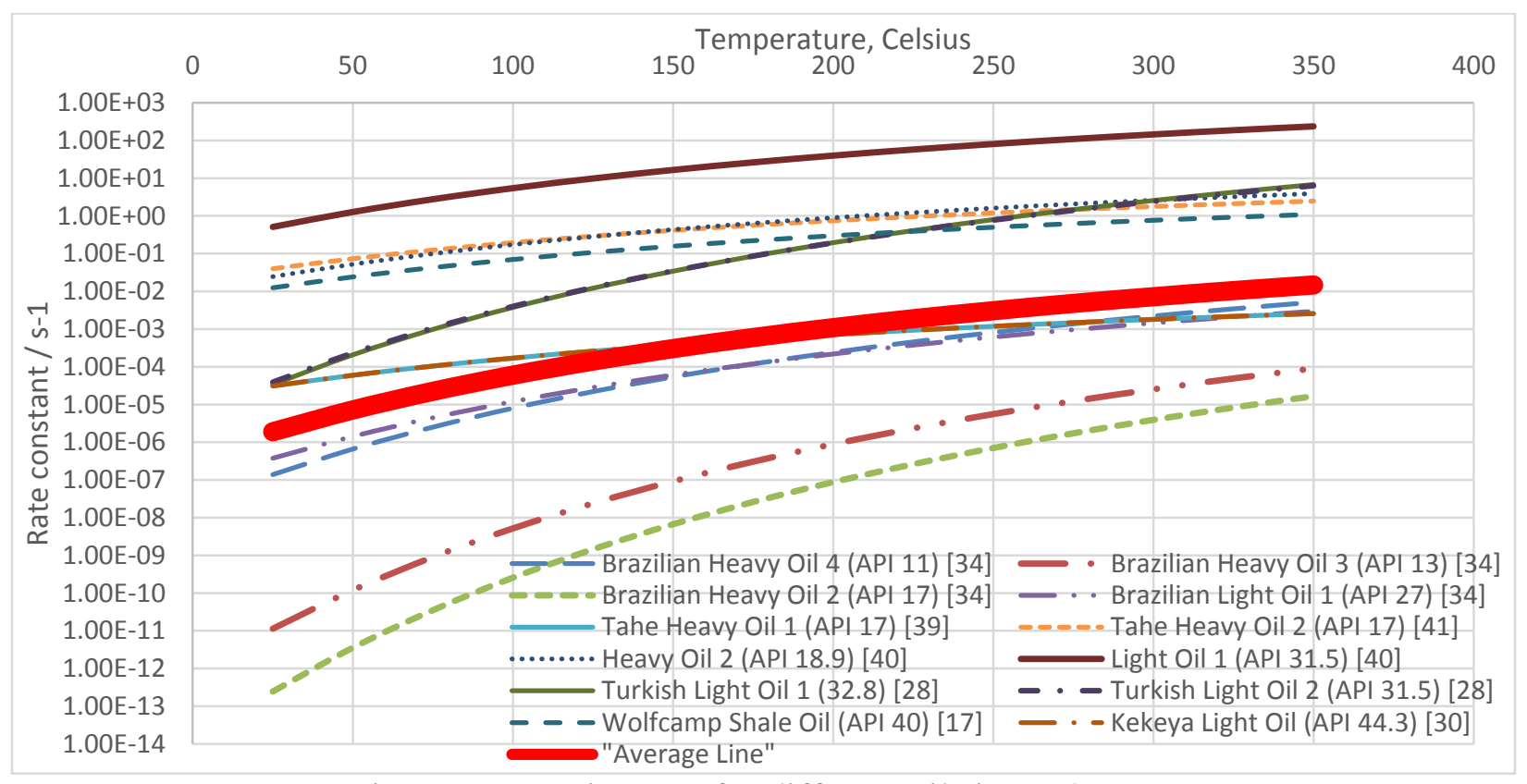

Figure 5, Reaction rate for different oils in LTO stage 


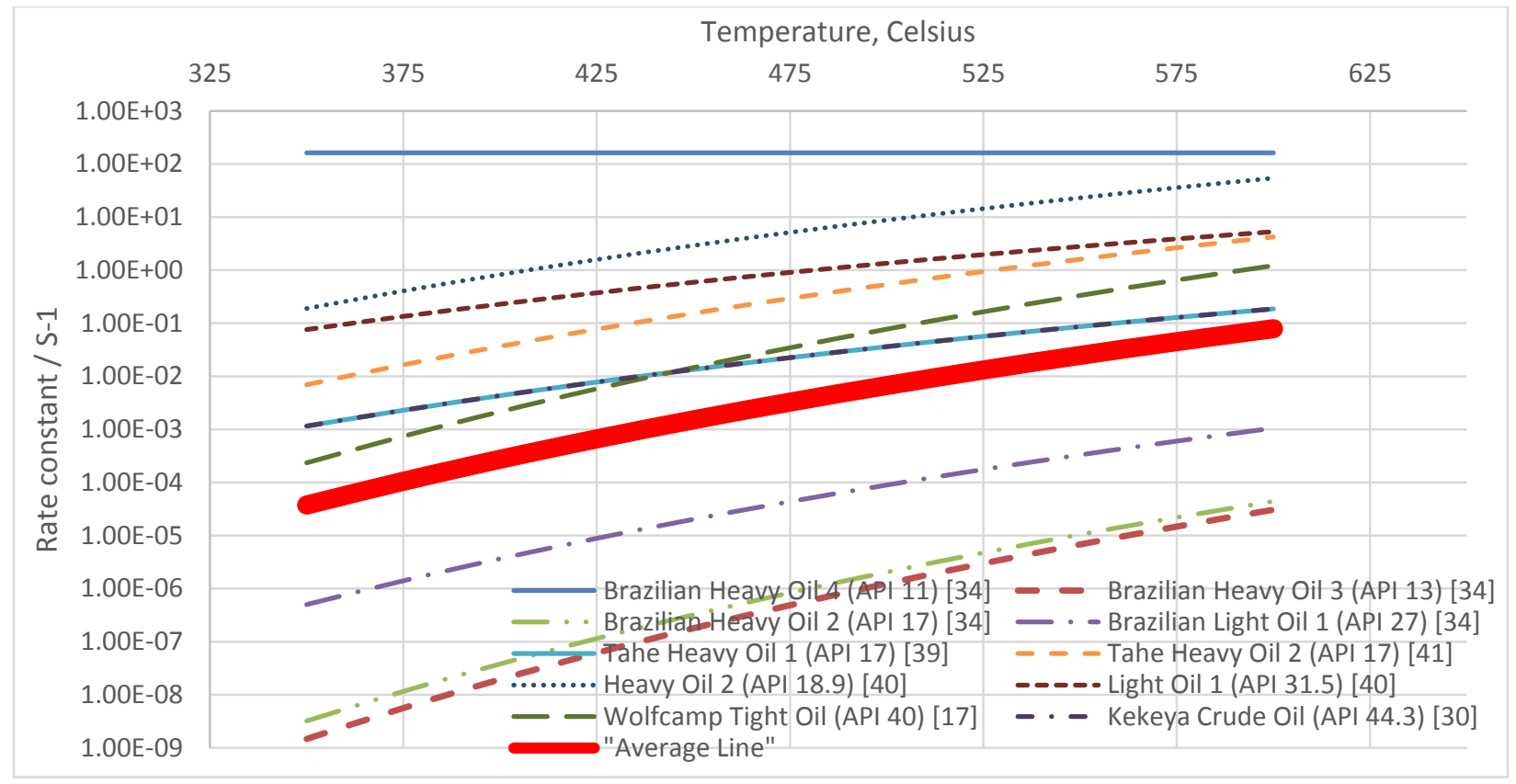

Figure 6, Reaction rate for different oils in HTO stage

\section{Sensitivity study on experimental parameters}

The original objective of thermal studies was to develop an inexpensive and rapid screening test workflow to evaluate the feasibility of AIP. However, because the experiments are not able to simulate the combustion tube condition or a field combustion environment, most of the objectives of those "screening tests" became instead to test the sensitivity of the experimental parameters. The most commonly measured experimental parameters are pressure and the presence of additives. Additionally, the reservoir pressure condition and the rock type of the reservoir are the most relevant parameters to a field practice and a simulation test. Therefore, understanding the effect of pressure and the presence of additives on thermal behavior as well as the kinetic data can bring more effective conclusions for the operators.

\subsection{Pressure effect}

It is acknowledged that an increase of pressure results in an increase in reaction rate and heat released from reactions [5, 43]. Also, as the pressure increases, the oxidation reactions will shift to lower temperature ranges. This phenomenon occurs because decreasing of pressure will slow the oxidation reactions by decreasing the frequency factors [42, 45]. According to Bae et al. [5], as the pressure increased from $50 \mathrm{psig}$ to $1000 \mathrm{psig}$, the peak exothermic temperature decreased from $315{ }^{\circ} \mathrm{C}$ to around $248{ }^{\circ} \mathrm{C}$. Also, the research showed when the pressure is $1000 \mathrm{psig}$, LTO 
could generate more heat than the HTO stage. Similar observations has also been described by Li et al. [43]. In their experiments, they also observed the increase of pressure can significantly enhance heat generation in the LTO stage for a light and a medium oil. The reason for this is believed to be that the increase of pressure extends the flammable limits for distilled hydrocarbon vapor. They also studied the pressure effect for the bitumen. For bitumen, the increase of pressure is more pronounced in its HTO stage. Therefore, it indicates that the pressure effect will be dependent upon the compositions of the crude oils. Both Bae et al. and Li et al. reported that a light crude oil presents a strong reactive behavior in the LTO stage once the pressure increases. The strong reactive behavior in LTO actually is an indication that more available heat could be used to sustain the combustion front if combustion is initiated. Thus, this behavior is a good sign for the HPAI process in a light oil reservoir.

Yoshiki et al. [42] stated variation of pressure will not affect activation energy data in LTO. A similar observation was also made by Kok [32]. He conducted a series of experiments and provided the pressure effect on kinetic data. The results show that as the pressure increased from $0.1 \mathrm{Mpa}$ to $2 \mathrm{Mpa}$, the activation energy in the HTO generally decreased around $39 \% \sim 85 \%$. However, the variations of activation energy in LTO are very small, which can be ignored when comparing the variations in the HTO stage.

To summarize, pressure does not show strong effects on activation energies in the LTO stage, but as the pressure increased, it significantly decreased the activation energies in the HTO stage to around $39 \% \sim 85 \%$. Also, the increase of pressure can lead more heat generated in the LTO stage for a light oil, which is a promising sign for applying the HPAI in a light oil reservoir.

\subsection{Presence of additives effect}

Researchers have tested adding different additives into the oil to see their effects on the crude oil combustion process. Results indicate that additives such as pure quartz, sandstone, etc. only have a surface area effect on the combustion process. However, other additives such as clay minerals, metallic additives, etc. have been proven to have strong catalytic effect on the crude oil oxidation reactions. A typical examination method for the catalytic effect is to measure the activation energies with and without the presence of additives to the crude oil. If the activation energies 
decrease with addition of additives, it means the additive has catalytic effect upon the crude oil combustion process.

Vossoughi et al. [46] presented that kaolinite has catalytic effect on crude oil combustion, but sand has no effect. A similar finding was obtained by Sarma et al. [10], who reported the presence of rock can significantly raise the self-heating rate and increase the exothermic termination temperature. The kinetic data estimated from the ARC shows the presence of cutting $\mathrm{B}$ and $\mathrm{C}$ won't decrease the activation energy. While with the presence of cutting $\mathrm{A}$, the activation energy decreased around $48 \%$, from $50 \mathrm{KJ} / \mathrm{mol}$ to $26 \mathrm{KJ} / \mathrm{mol}$, which was due to the presence of clay content in cutting A. Huang et al. [18] compared the shale cuttings and sand cuttings effect on the oxidation reactions of the crude oil. The results show that after adding shale cuttings which contain clay minerals, the activation energies in the LTO stage decreased around $48 \%$, from $16.96 \mathrm{KJ} / \mathrm{mol}$ to $8.82 \mathrm{KJ} / \mathrm{mol}$, and decreased around $34 \%$, from $145 \mathrm{KJ} / \mathrm{mol}$ to $93 \mathrm{KJ} / \mathrm{mol}$ in the HTO stage. However, the sand does not show significant effect on the crude oil combustion process. Similar findings have also obtained by Kok [47, 48]. He conducted a series of thermal experiments to investigate the effect of clay on crude oil combustion, and the results showed a uniform trend of decreasing activation energies with the addition of clay. In the HTO stage, activation energies generally decreased around 3\% 51\%, from $98.6 \mathrm{KJ} / \mathrm{mol} \sim 101.8$ $\mathrm{KJ} / \mathrm{mol}$ to $48.5 \mathrm{KJ} / \mathrm{mol} \sim 97.7 \mathrm{KJ} / \mathrm{mol}$. Jia et al. [49] studied the effect of cuttings on the crude oil combustion process, and the results indicate that after adding cuttings, the activation energies in LTO increased $12 \% \sim 45 \%$, from $26.68 \mathrm{KJ} / \mathrm{mol}$ to $31.42 \mathrm{KJ} / \mathrm{mol} \sim 47.02 \mathrm{KJ} / \mathrm{mol}$, and decreased $45 \% \sim 55 \%$, from $153.05 \mathrm{KJ} / \mathrm{mol}$ to around $69.84 \mathrm{KJ} / \mathrm{mol} \sim 84.22 \mathrm{KJ} / \mathrm{mol}$ in the HTO region. The effects of different clays, including kaolinite, smectite, illite, and chlorite on the oxidation kinetics of the crude oil were also studied. The results show that after adding clay into the crude oil, the activation energies generally decrease around $37 \% \sim 86 \%$, from $153 \mathrm{KJ} / \mathrm{mol}$ to $22.18 \mathrm{KJ} / \mathrm{mol} \sim 96.15 \mathrm{KJ} / \mathrm{mol}$ in the HTO stage, while the activation energies slightly increased or were unchanged in the LTO stage. Smectite was also observed to have the strongest catalytic effect on crude oil combustion among other clay minerals [15]. Pu et al. [50] studied the effect of metallic additives on kinetic data for combustion reactions. Their results indicate that $\mathrm{CuCl}_{2}$ has an excellent catalytic effect on crude oil combustion. Activation energies in both the LTO and HTO regions have been reduced after adding metallic additives. Activation energies in the LTO 
stage decreased around $9 \% \sim 30 \%$, from $19 \mathrm{KJ} / \mathrm{mol}$ to $13.78 \mathrm{KJ} / \mathrm{mol} \sim 17.76 \mathrm{KJ} / \mathrm{mol}$ and around $9 \% \sim 65 \%$, from $116.03 \mathrm{KJ} / \mathrm{mol}$ to $40.65 \mathrm{KJ} / \mathrm{mol} \sim 105.58 \mathrm{KJ} / \mathrm{mol}$ in the HTO stage.

To summarize, with the presence of sands or quartz, the activation energies stays almost unchanged or increases slightly. On the other hand, after adding additives such as clay minerals or metallic additives which have a catalytic effect on crude oil combustion reactions, the activation energies will generally decrease around 30\% 70\% in the HTO stage, while no obvious effects on the LTO stage were observed. Fig 7 below shows the activation energy distribution of crude oil with the presence of additives which includes 25 cases [6, 10, 15, 18, 33, 34, 35, 48-54]. It is observed that the activation energy in the HTO $(73 \mathrm{KJ} / \mathrm{mol})$ stage is higher than the LTO $(26$ $\mathrm{KJ} / \mathrm{mol}$ ) stage. A general range of activation energy for oil with presence of additives are $18 \sim 43$ $\mathrm{KJ} / \mathrm{mol}$ for the LTO stage and $60 \sim 100 \mathrm{KJ} / \mathrm{mol}$ for the HTO stage.

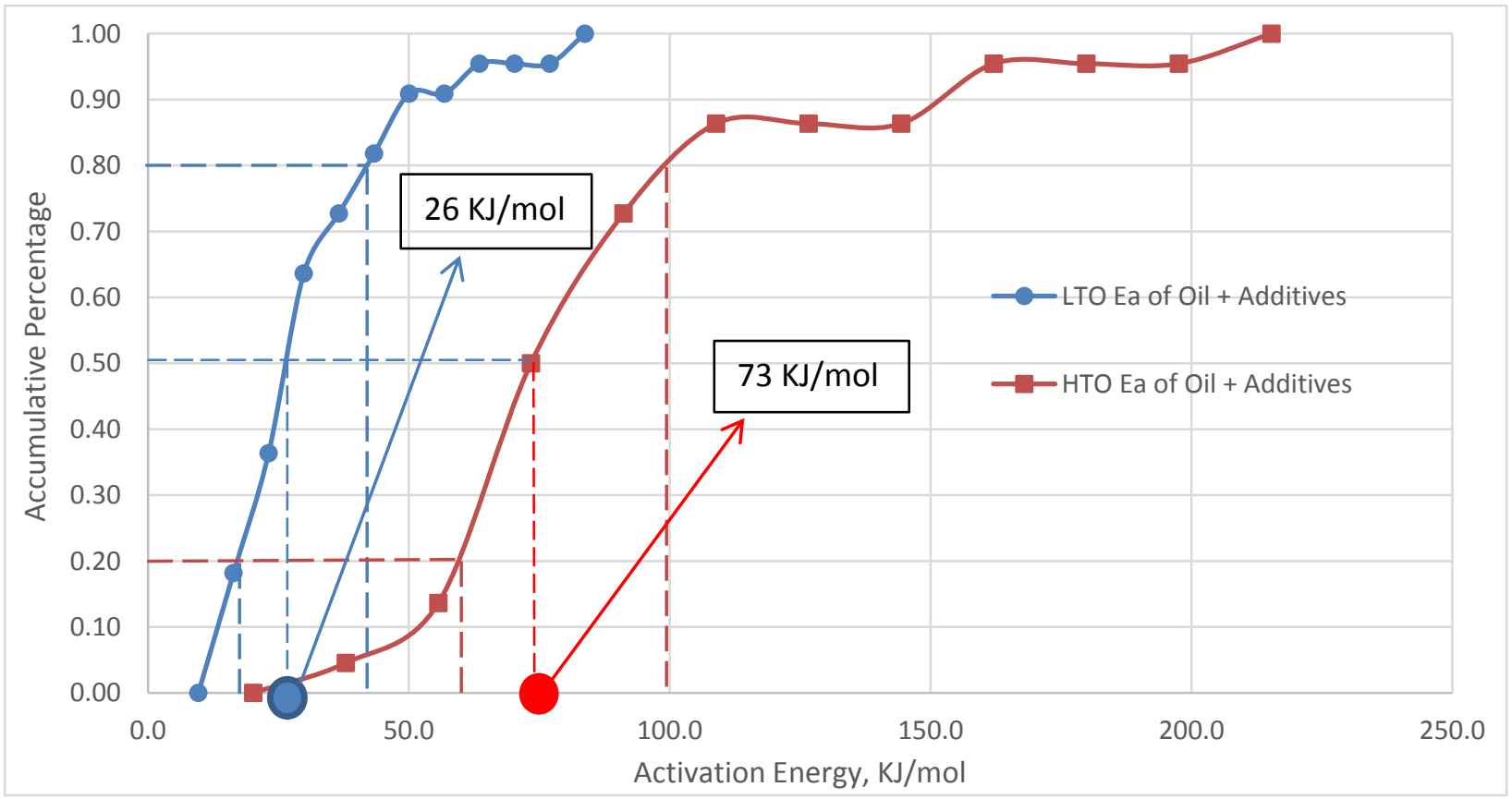

Figure 7, Activation energy of 25 crude oil samples with the presence of additives

\section{Numerical simulation study}

In this section, simulation approach is utilized to study the effects of the parameters from the screening experiments on thermal behavior and EOR performance. 


\subsection{Base reservoir simulation model}

A base reservoir simulation model was built in CMG STARS based upon the Tingas's model which was described in his thesis [55]. The base model is justified by the fact that the model can predict a field oil recovery of $52.5 \%$ after 10 years of air injection. The field oil recovery was reported by Tingas in Table 5.6 of his thesis [55]. The grid size effect has been investigated through the simulation process, which does not show a strong effect on the recovery performance. The initial reservoir pressure is 6440 psia and the initial temperature is $99{ }^{\circ} \mathrm{C}$. The initial oil and water saturations are 0.55 and 0.45 , respectively. The total grid block size of the model is $2742 \mathrm{ft}$ $* 865 \mathrm{ft} * 175 \mathrm{ft}$ with a 3-D Cartesian grid of $22 * 9 * 5$ with 990 active blocks in the model. The reservoir has a 15 degree dip angle, and the top depths of each grid column varies from $8620 \mathrm{ft}$ to $8200 \mathrm{ft}$. Two horizontal wells are set in the reservoir. The injection well is located in the updip region of the reservoir, and the production well is located in the downdip region of the reservoir as shown in Fig 8. The injection rate for the injector is $4.8^{*} 10^{6} \mathrm{ft}^{3} /$ day. The oil properties used in this model are from the North Sea light crude oil, which has $0.55 \mathrm{cP}$ viscosity and $40.2^{\circ} \mathrm{API}$ gravity. There are 5 oil components which are $\mathrm{C}_{21+}, \mathrm{C}_{11-20}, \mathrm{C}_{6-10}, \mathrm{C}_{2-5}, \mathrm{CH}_{4}$, and six other components which are $\mathrm{H}_{2} \mathrm{O}, \mathrm{CO}_{2}, \mathrm{CO}, \mathrm{N}_{2}, \mathrm{O}_{2}$, Coke set in the model [55]. The components properties are shown in Table 1 below. The phase behavior of the pseudo components was estimated from CMG-Winprop by $\mathrm{K}$-value tables. The reaction scheme is shown in Table 2, which contains three cracking reactions and seven combustion reactions.

Table 1, Component properties of the simulation model

\begin{tabular}{|c|c|c|c|c|}
\hline Component & Reference Phase & Pcrit, psi & Tcrit, $\mathbf{F}$ & MW, Ib/lbmol \\
\hline WATER & Water Phase & 0 & 0 & 0 \\
\hline C21+ & Oleic Phase & 171 & 1051.17 & 447.53 \\
\hline C11-20 & Oleic Phase & 266.56 & 837.64 & 218.38 \\
\hline C6-10 & Oleic Phase & 424.71 & 563.38 & 110.29 \\
\hline C2-5 & Oleic Phase & 579.02 & 249.13 & 72.15 \\
\hline CH4 & Oleic Phase & 667.2 & -116.59 & 16.043 \\
\hline CO2 & Oleic Phase & 1069.87 & 87.89 & 44.01 \\
\hline N2 & Oleic Phase & 492.31 & -232.51 & 28.013 \\
\hline O2 & Gaseous Phase & 731.86 & -181.39 & 31.999 \\
\hline CO & Gaseous Phase & 507.052 & -220.45 & 28.01 \\
\hline COKE & Solid Phase & & & 13.6 \\
\hline
\end{tabular}




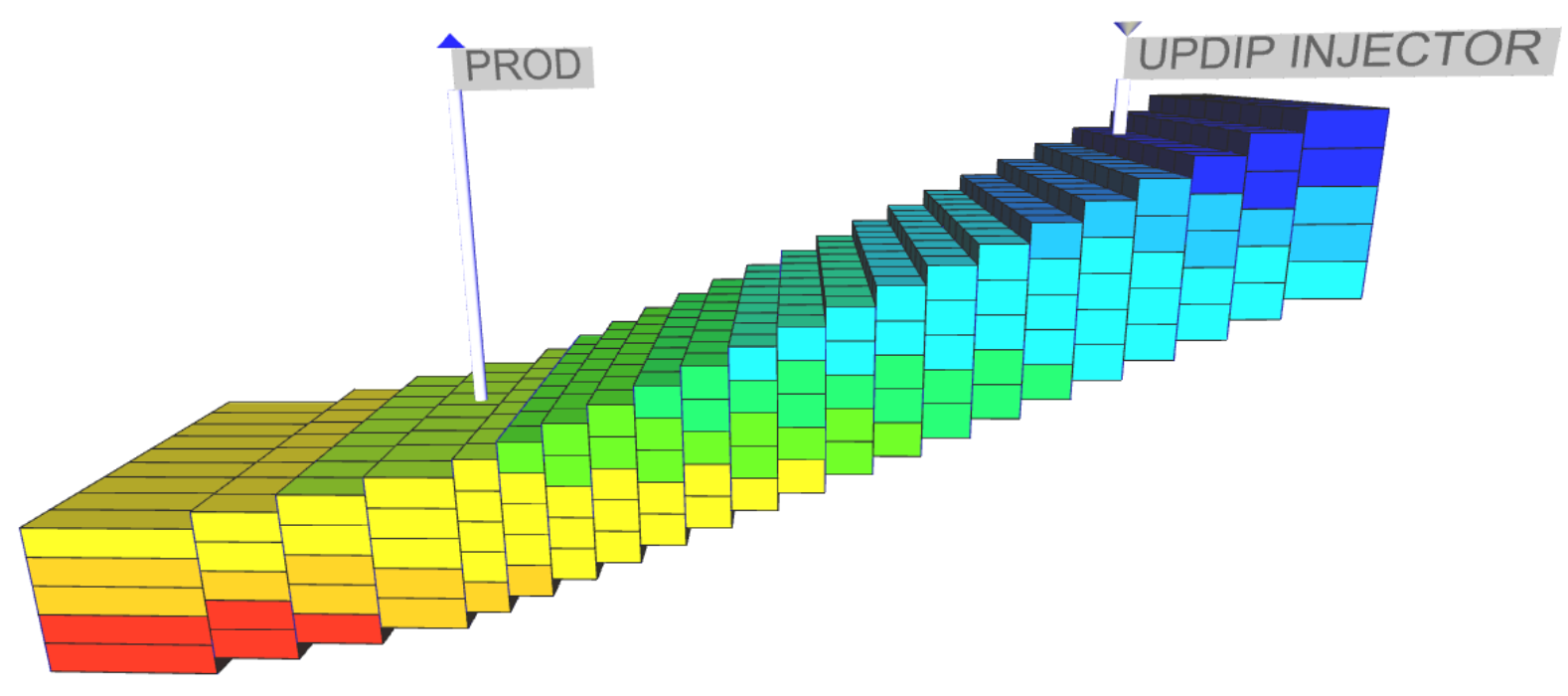

Figure 8. Reservoir simulation model

Table 2, Reaction scheme of the simulation study

\begin{tabular}{|c|c|c|c|c|c|}
\hline Number & Reactions & Reaction Formula & $\begin{array}{l}\text { Enthalpy, } \\
\text { Btu/lbmol }\end{array}$ & $\begin{array}{c}\text { Ea, } \\
\mathrm{KJ} / \mathbf{m o l}\end{array}$ & Ar, s-1 \\
\hline 1 & $\begin{array}{l}\text { C21+ Cracking (with } \\
\text { CH4 generation) }\end{array}$ & $\begin{aligned} \mathrm{C} 21+==> & 6.18 \mathrm{CH} 4+24.98 \\
& \text { COKE }\end{aligned}$ & 0 & 88 & $1.27 \mathrm{E}+05$ \\
\hline 2 & $\begin{array}{c}\text { C21+ Cracking (without } \\
\text { CH4 generation) }\end{array}$ & $\begin{array}{c}\mathrm{C} 21+==> \\
\text { COKE } \\
\text { COK } 2-5+14.449 \\
\end{array}$ & 0 & 91 & $8.91 E+04$ \\
\hline 3 & C11-20 Cracking & $\begin{array}{c}\mathrm{C} 11-20==>3.494 \mathrm{CH} 4+ \\
11.953 \mathrm{COKE}\end{array}$ & 0 & 105 & $5.00 E+04$ \\
\hline 4 & C21+ Combustion & $\begin{array}{c}\mathrm{C} 21++41.85 \mathrm{O} 2==>39.287 \\
\text { WATER }+38.51 \mathrm{CO}\end{array}$ & 10293.9 & 29 & $3.85 E+10$ \\
\hline 5 & C11-20 Combustion & $\begin{array}{c}\mathrm{C} 11-20+15 . \mathrm{O} 2==>15.888 \\
\text { WATER }+14.829 \mathrm{CO}\end{array}$ & 4920.3 & 33 & $3.85 \mathrm{E}+10$ \\
\hline 6 & C6-10 Combustion & $\begin{array}{c}\text { C6-10 + 7.39 O2 ==> } 8.115 \\
\text { WATER + 7.152 CO }\end{array}$ & 2420.2 & 33 & $3.85 \mathrm{E}+10$ \\
\hline 7 & C2-5 Combustion & $\begin{array}{c}\mathrm{C} 2-5+3.734 \mathrm{O} 2==>4.41 \\
\text { WATER + 4.015 CO }\end{array}$ & 1463.4 & 33 & $3.85 E+10$ \\
\hline 8 & COKE Combustion & $\begin{array}{c}\mathrm{COKE}+1.4 \mathrm{O} 2==>0.8 \mathrm{H} 2 \mathrm{O}+ \\
\mathrm{CO} 2\end{array}$ & 461.3 & 13 & $3.00 E+05$ \\
\hline 9 & CH4 Combustion & $\begin{array}{c}\mathrm{CH} 4+1.5 \mathrm{O} 2==>2 \mathrm{H} 2 \mathrm{O}+1 \\
\mathrm{CO}\end{array}$ & 1463.4 & 35 & $3.85 E+10$ \\
\hline 10 & CO Combustion & $\mathrm{CO}+0.5 \mathrm{O} 2==>\mathrm{CO} 2$ & $2.84 \mathrm{E}+05$ & 8 & $1.91 \mathrm{E}+05$ \\
\hline
\end{tabular}

Fig 9 shows the recovery performance of the simulation model when displaced by air, $\mathrm{CO}_{2}$ and $\mathrm{N}_{2}$. It is observed that the recovery performance of air and $\mathrm{CO}_{2}$ is much higher than the recovery efficiency of $\mathrm{N}_{2}$. Air also shows a little higher recovery efficiency than $\mathrm{CO}_{2}$. This little better 
performance may be caused by the "bulldozing effect" of air injection process. This "bulldozing" effect has been discussed by Gutierrez et al. [1]. The bulldozing effect refers to that mechanism that a combustion front acts as a bulldozer to mobilize most of the oil immediately ahead of it, and the air fingering is reduced by the oil ahead of it. The oil could not be displaced earlier by other driving mechanisms like flue gas sweeping hot water or steam displacement. The track of the combustion front in one layer of grids from the injection well to the production well during the air injection process is shown in Fig 10. The combustion front was identified as the temperature peak which was initiated and sustained at around $193{ }^{\circ} \mathrm{C}$. The combustion front temperature is lower than that generally sustained in a heavy oil reservoir, and this behavior is caused by the different oxidation reaction mechanisms between light oil and heavy oil to the air injection. Figure 11 shows the oil saturation profile of the same layer of grids shown in Fig 10. It is observed that after initiating the combustion front, the oil saturation suddenly decreased, and the oil inside the grid block was totally displaced afterwards.

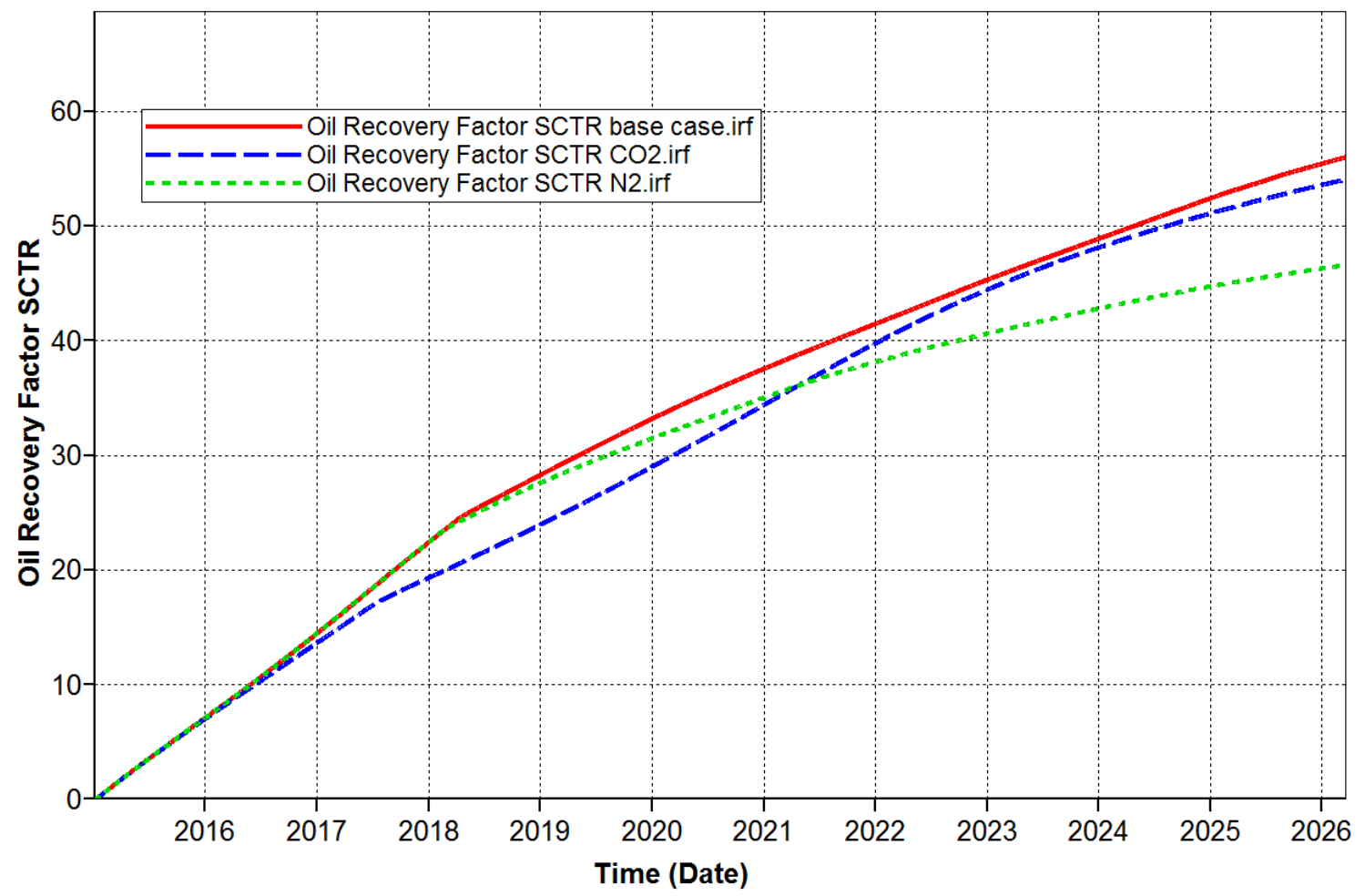

Figure 9, Recovery performance by using air shown as base case, $\mathrm{CO}_{2}$ and $\mathrm{N}_{2}$ 


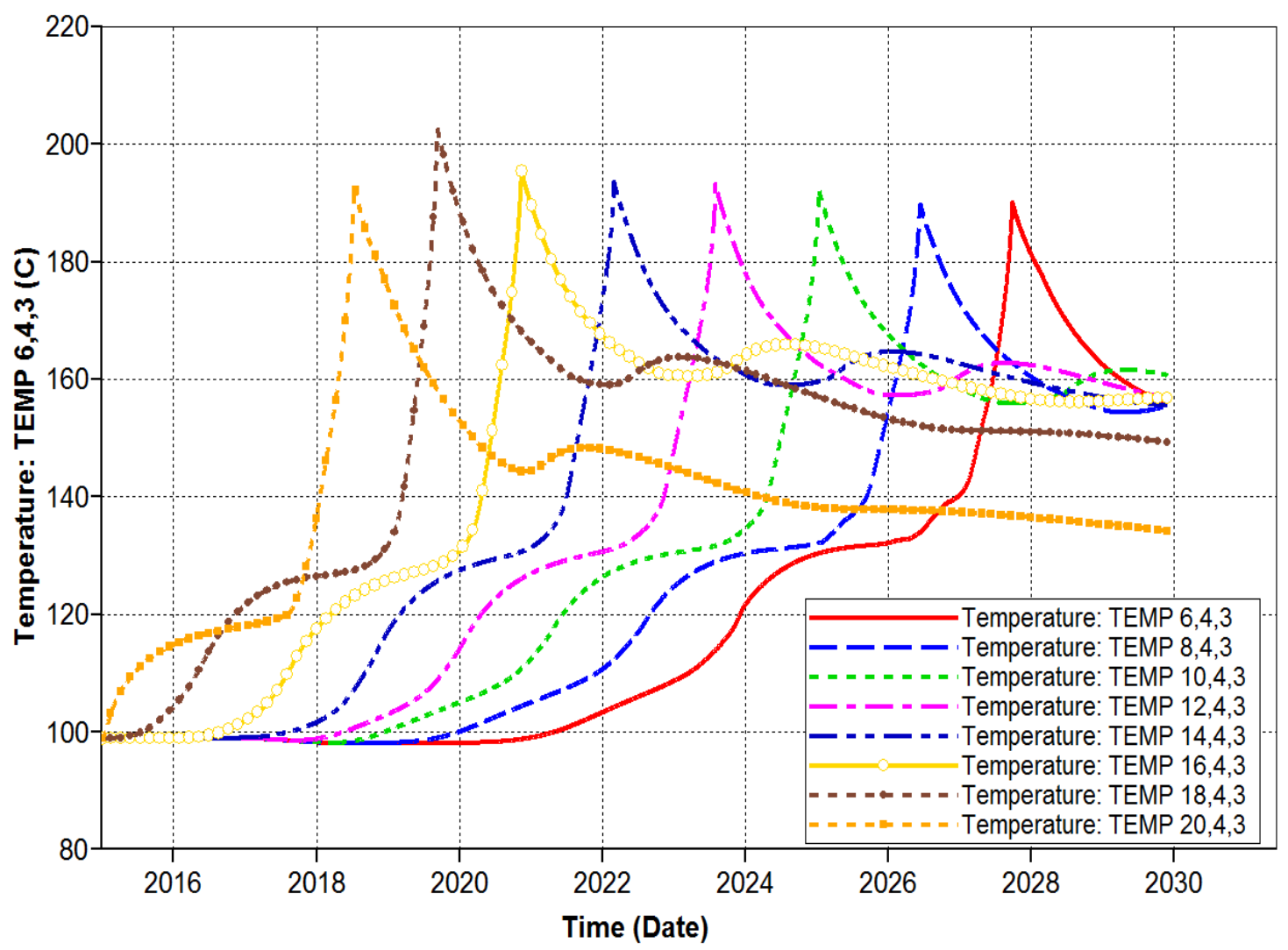

Figure 10. Combustion Front from injector to producer

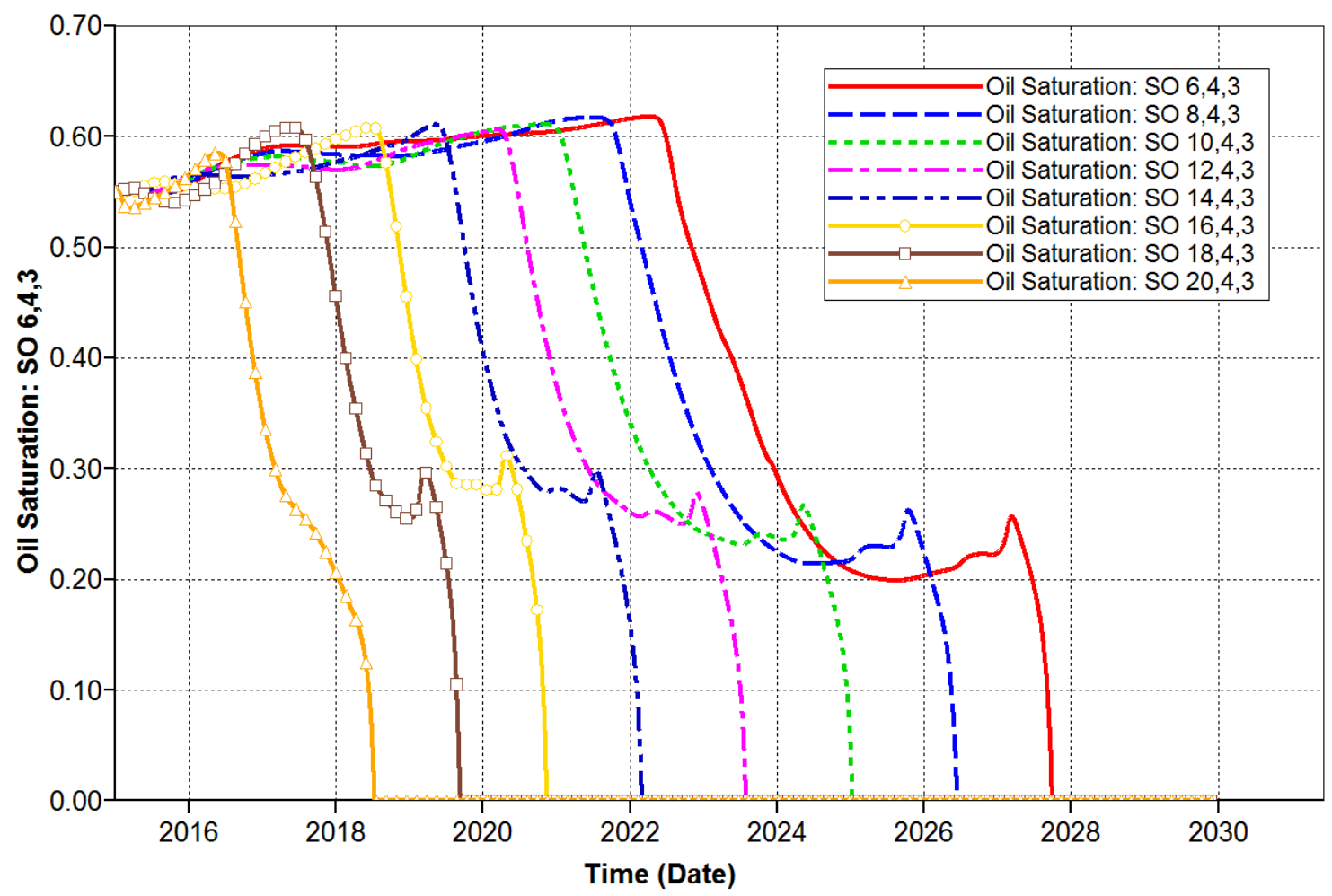

Figure 11. Oil saturation from injector to producer 


\subsection{Sensitivity study of kinetic data on recovery performance}

The focus of this simulation work is to investigate the effect of kinetic data on the air injection process. By using the activation energy and frequency factor values collected from the review section, several cases were run with different activation energy and frequency factor to observe the recovery performance and the reaction difference during the air injection process. Based on the reaction scheme shown in Table 2, reaction 1,2, 3 are grouped into cracking reaction group and reaction 4, 5, 6, 7 are grouped into combustion reaction group. In order to investigate the effect of the crude oil's kinetic data on the production performance in the combustion reactions, only combustion reaction group is tested by changing their kinetic data. The kinetic data values for these reactions are assumed to be the same. These reactions are for pseudo components and have uncertainties. The other reactions are kept unchanged. Also, in order to investigate the effect of the crude oil's kinetic data on the production performance in the cracking reactions, only cracking reaction group is tested and the kinetic data in this group of reactions are assumed to be the same. For the cracking reaction group, the activation energy was tested from $70 \mathrm{KJ} / \mathrm{mol}$ to $130 \mathrm{KJ} / \mathrm{mol}$ and the frequency factor was tested from $10^{1} \mathrm{~s}^{-1}$ to $10^{9} \mathrm{~s}^{-1}$. For combustion reaction group, the test range of the activation energy is set from $35 \mathrm{KJ} / \mathrm{mol}$ to $130 \mathrm{KJ} / \mathrm{mol}$ and $10^{1} \mathrm{~s}^{-1}$ to $10^{9} \mathrm{~s}^{-1}$ of the frequency factor.

Fig 12 shows the temperature profile of the observation grid block and the recovery performance of the air injection process under different frequency factor values. It is observed that different frequency factor values did not show a significant effect on neither recovery performance nor the ignition behavior of the air injection process. 


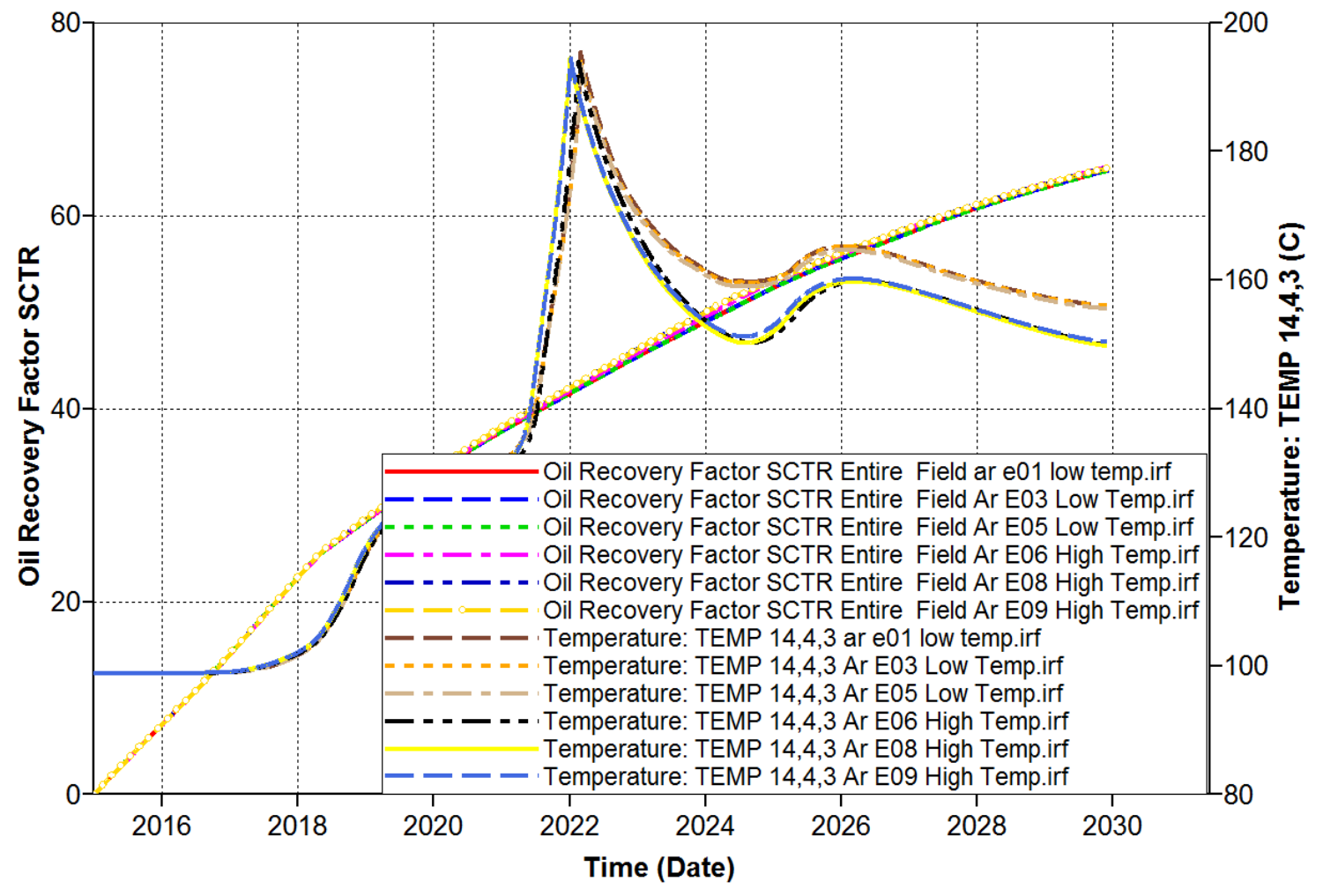

Figure 12, Temperature profile of the observation grid block and the recovery performance of the air injection process under different frequency factor values

Table 3 displaces the effect of activation energy on the recovery performance of the reservoir. It is observed that the variation of the activation energy values in both combustion reactions and cracking reactions are sensitive to the recovery performance, and the effects of the variation of the activation energy on the low temperature reactions and the high temperature reactions on the recovery performance are the same. As shown in Table 3 that the recovery factors increase with the decrease of the activation energy in the combustion reaction tests. By changing the activation energy from $130 \mathrm{KJ} / \mathrm{mol}$ to $50 \mathrm{KJ} / \mathrm{mol}$, the recovery factor increased around $10 \%$. The temperature profile of an observation grid block under different activation energy values is displaced in Fig 13. This grid block is located around the middle of the injection well and the production well. It is observed in Fig 13, that a higher activation energy of the combustion reaction will delay the initiation of the spontaneous ignition. This is because with a higher activation energy, it is more difficult to initiate the combustion reactions, which will delay the spontaneous ignition. As stated previously, in this simulation, the main AIP recovery mechanism is caused by the combustion front displacement. If the initiation of the combustion front is 
delayed or the spontaneous ignition cannot be achieved, the recovery performance will be damaged significantly. Fig 13 shows when the activation energy is higher than $100 \mathrm{KJ} / \mathrm{mol}$, the combustion front is never achieved during the whole AIP, which caused the recovery factor decreased significantly.

For cracking reactions, a lower activation energy also results in a higher recovery performance. It is observed in Table 3 that as the activation energy decreases from $180 \mathrm{KJ} / \mathrm{mol}$ to $80 \mathrm{KJ} / \mathrm{mol}$, the recovery factor increases from $52.2 \%$ to $52.6 \%$. It is seen that the effect of the cracking reaction's activation energy to the recovery performance is less sensitive than the effect of the combustion reaction's activation energy to the recovery performance. The reason is when changing the activation energy in the cracking reactions, it will not significantly affect the initiation of the combustion front as shown in Fig 14. In fact, the increase of the recovery factor with a lower activation energy is due to the increase of the $\mathrm{CO}_{2}$ concentration. Since cracking reactions generate $\mathrm{CH}_{4}, \mathrm{C}_{2-5}$, and Coke. Therefore, as the activation energy lowers, the concentrations of these products increase due to the stronger reactivity of the cracking reactions, then the $\mathrm{CO}_{2}$ concentration increases. The $\mathrm{CO}_{2}$ concentration profile with different activation energy values is shown in Fig 14. It is seen that with a lower activation energy, $\mathrm{CO}_{2}$ concentration is higher. A higher $\mathrm{CO}_{2}$ concentration will increase the potential miscibility flooding by the $\mathrm{CO}_{2}$, thus increasing the oil recovery. Therefore, the variation of the activation energy in the high temperature cracking reactions will affect the EOR by influence the $\mathrm{CO}_{2}$ generation.

To summarize, the variation of the frequency factor does not show a significant effect on the recovery performance. And the observation of the effect of the activation energy is in accordance to the screening criteria which was summarized in the third section, that a lower activation energy will be more favorable for the recovery performance. The effect of the combustion reactions' activation energy to the recovery performance is more significant than the effect of the cracking reactions' activation energy to the recovery performance. The reason is the combustion reactions can significantly affect the initiation of the combustion front while the cracking reactions cannot.

Table 3, Effect of activation energy on reservoir recovery performance 


\begin{tabular}{|c|c|c|}
\hline Reaction & Ea KJ/mol & RF in 10 years \% \\
\hline \multirow{3}{*}{ Cracking Reaction 1, 2, 3 } & 80 & 52.6 \\
\cline { 2 - 3 } & 90 & 52.4 \\
\cline { 2 - 3 } & 130 & 52.2 \\
\cline { 2 - 3 } & 180 & 52.2 \\
\hline \multirow{3}{*}{$\begin{array}{c}\text { Combustion Reaction 4, 5, 6, } \\
\text { 7 }\end{array}$} & 50 & 57.6 \\
\cline { 2 - 3 } & 70 & 56.9 \\
\cline { 2 - 3 } & 90 & 56 \\
\cline { 2 - 3 } & 100 & 55 \\
\cline { 2 - 3 } & 130 & 47.5 \\
\hline
\end{tabular}

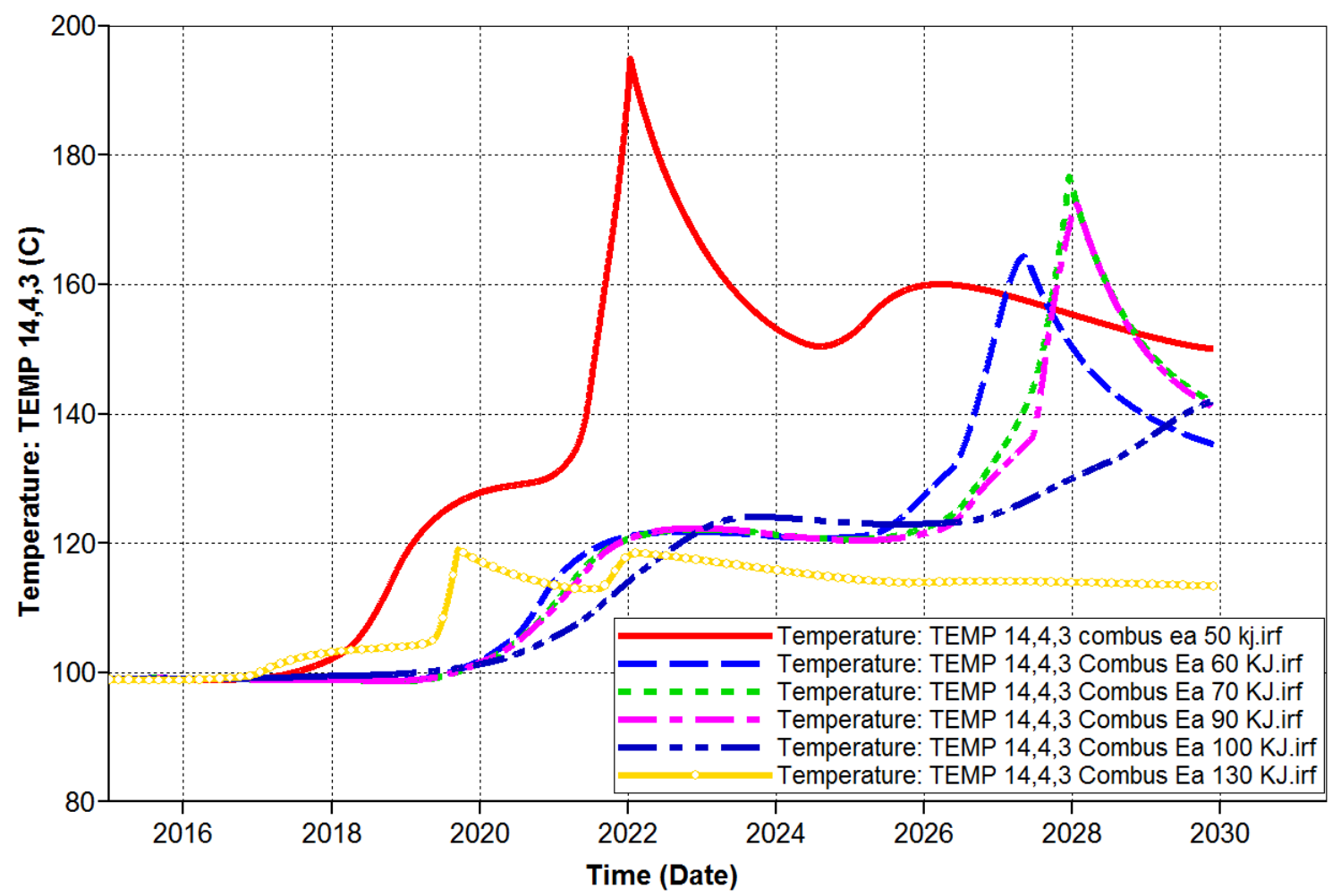

Figure 13, Temperature profile of the observation grid block under different activation energy in combustion reactions 


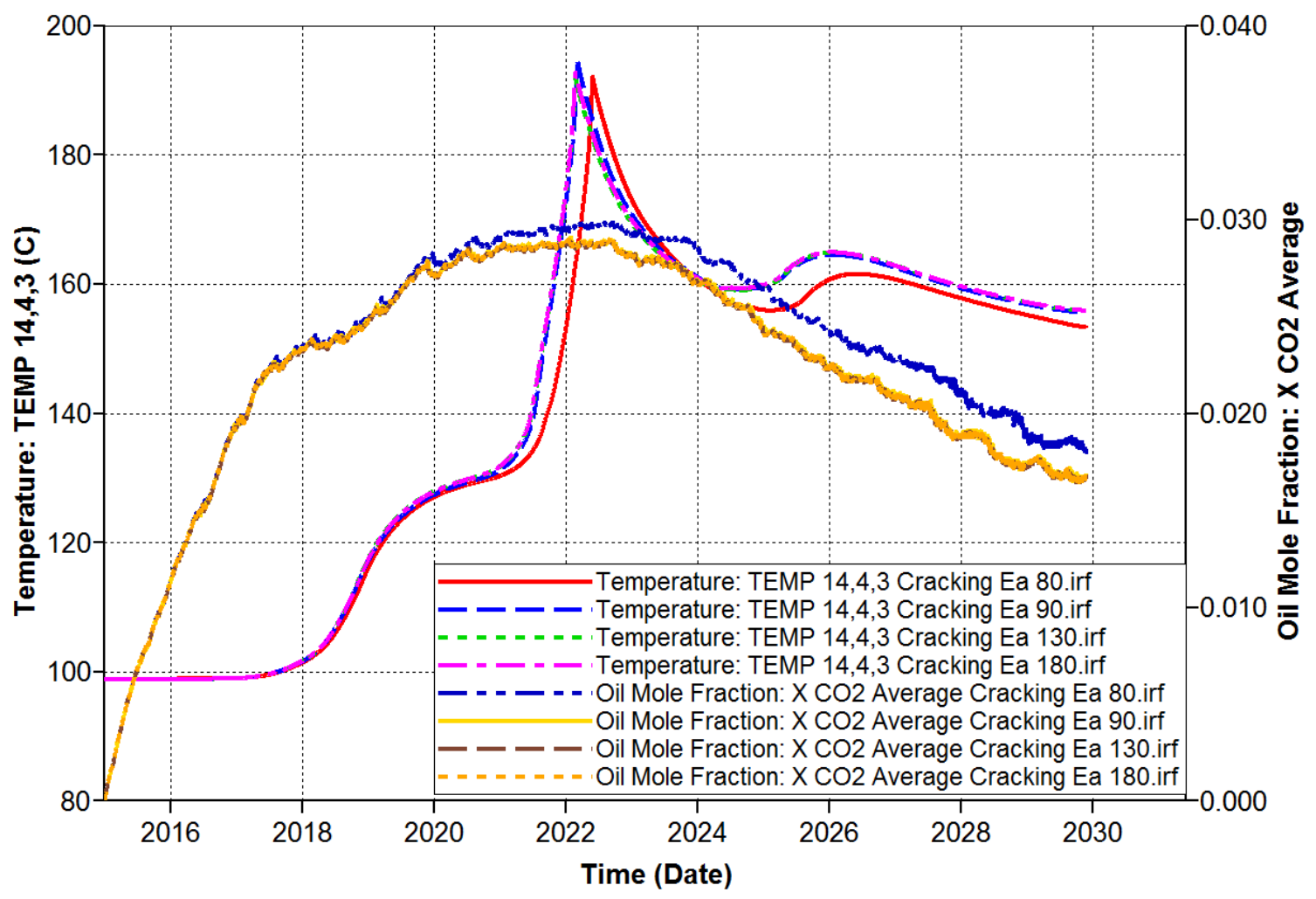

Figure 14, Reservoir $\mathrm{CO}_{2}$ concentration and observation block temperature profile with different activation energy of cracking reactions

\section{Conclusions}

The following conclusions may be drawn from this study.

- Thermal experiments have two main roles.

1) To work as a low-cost method to pre-screen the candidate oils before conducting combustion tube tests;

2) To estimate the relevant kinetic data and study the thermo-oxidative behavior, and develop the base model before conducting combustion tube tests.

- The API gravity of the crude oil has no relation to the reaction temperature regions and the kinetic data of the crude oil.

- The reaction temperature ranges for LTO and HTO were estimated to be $149 \sim 364{ }^{\circ} \mathrm{C}$ for the LTO and $415 \sim 542{ }^{\circ} \mathrm{C}$ for the HTO. And the average combustion peak temperature are 320 ${ }^{\circ} \mathrm{C}$ in the LTO stage and $469{ }^{\circ} \mathrm{C}$ in the HTO stage.

- The activation energy in HTO $(107 \mathrm{KJ} / \mathrm{mol})$ is generally higher than that in the LTO (33 $\mathrm{KJ} / \mathrm{mol}$ ). The general activation energy ranges for a crude oil are $20 \sim 70 \mathrm{KJ} / \mathrm{mol}$ in the LTO 
stage and $70 \sim 180 \mathrm{KJ} / \mathrm{mol}$ in the HTO stage. Also, the frequency factor in the LTO $(0.1 \sim$ $\left.10^{5} \mathrm{~s}^{-1}\right)$ are generally lower than that in the HTO $\left(10^{4} \sim 10^{9} \mathrm{~s}^{-1}\right)$.

- With the presence of the additives such as cuttings and metallic additives, the general activation energy ranges for a crude oil are $18 \sim 43 \mathrm{KJ} / \mathrm{mol}$ in the LTO stage and $60 \sim 100$ $\mathrm{KJ} / \mathrm{mol}$ in the HTO stage. High pressure environments could decrease the activation energy in the HTO stage to around $39 \sim 85 \%$, while they do not show a significant effect on the LTO stage's activation energy.

- A lower activation energy is more favorable for oil recovery, but the frequency factor may not.

\section{Acknowledgment}

This work is supported by the U.S. Department of Energy under Award No. DE-FE0024311.

\section{Nomenclature}

AIP - air injection process

EOR - enhanced oil recovery

LTO - low temperature oxidation

HTO - high temperature oxidation

TGA - thermogravimetric analysis

DSC - differential scanning calorimetry

ARC - accelerating rate calorimetry

SBR - small batch reactor

ISC - in-situ combustion

DTA - differential thermal analyzer

FD - fuel deposition

PDSC - pressurized differential scanning calorimetry

$\mathrm{Ea}$ - activation energy, $\mathrm{KJ} \mathrm{mol}^{-1}$

Ar - frequency factor, $\mathrm{s}^{-1}$

$\mathrm{R}$ - universal gas constant, $\mathrm{J}_{\mathrm{mol}}{ }^{-1} \mathrm{~K}^{-1}$

$\mathrm{K}(\mathrm{T})$ - reaction rate, $\mathrm{s}^{-1}$ 


\section{References}

[1]. Gutierrez, D., Skoreyko, F., Moore, R. G., Mehta, S. A., \& Ursenbach, M. G. The challenge of predicting field performance of air injection projects based on laboratory and numerical modelling. Journal of Canadian Petroleum Technology, 2009.48(04), 23-33.

[2]. Hughes, B., \& Sarma, H. K. Burning reserves for greater recovery? Air injection potential in Australian light oil reservoirs. In SPE Asia Pacific Oil \& Gas Conference and Exhibition. Society of Petroleum Engineers. 2006.

[3]. Niz-Velasquez, E., Trujillo-Portillo, M. L., Delgadillo, C., \& Padilla, J. A Methodology for Screening and Ranking of Reservoirs for Light Oil Air Injection Implementation. In SPE Energy Resources Conference. Society of Petroleum Engineers. 2014.

[4]. Tadema, H. J. Mechanism of oil production by underground combustion. In 5th World petroleum congress. World Petroleum Congress. 1959. 22.

[5]. Bae, J. H. Characterization of crude oil for fireflooding using thermal analysis methods. Society of Petroleum Engineers Journal, 1977.17(03), 211-218.

[6]. Vossoughi, S., Bartlett, G. W., \& Willhite, G. P. Development of a kinetic model for in-situ combustion and prediction of the process variables using TGA/DSC techniques. In SPE annual technical conference and exhibition. Society of Petroleum Engineers. 1982.

[7]. Kharrat, R., \& Vossoughi, S. Feasibility study of the in-situ combustion process using TGA/DSC techniques. Journal of petroleum technology, 1985.37(08), 1-441.

[8]. Yannimaras, D. V., \& Tiffin, D. L. Screening of oils for in-situ combustion at reservoir conditions via accelerating rate calorimetry. SPE Reservoir Engineering, 1995.10(01), 36-39.

[9]. Fraim, M. L., Moffitt, P. D., \& Yannimaras, D. V. Laboratory testing and simulation results for high pressure air injection in a waterflooded North Sea oil reservoir. In SPE Annual Technical Conference and Exhibition. Society of Petroleum Engineers.1997.

[10]. Sarma, H. K., Yazawa, N., Moore, R. G., Metha, S. A., Okazawa, N. E., Ferguson, H., \& Ursenbach, M. G. Screening of three light-oil reservoirs for application of air injection process by accelerating rate calorimetric and TG/PDSC tests. Journal of Canadian Petroleum Technology, 2002.41(03).

[11]. Sarma, H. K., \& Das, S. C. Air injection potential in Kenmore oilfield in Eromanga Basin, Australia: a screening study through thermogravimetric and calorimetric analyses. In SPE Middle East Oil and Gas Show and Conference. Society of Petroleum Engineers. 2009.

[12]. Li, J., Mehta, S. A., Moore, R. G., Ursenbach, M. G., Ferguson, H., Zalewski, E., \& Okazawa, N. E. The Research of Oxidation and Ignition Behaviour of Saturated Hydrocarbon Sample with Crude Oils Using TG/DTG and DTA Thermal Analysis Techniques. In Canadian International Petroleum Conference. Petroleum Society of Canada. 2002.

[13]. Drici, O., \& Vossoughi, S. Study of the surface area effect on crude oil combustion by thermal analysis techniques. Journal of petroleum technology, 1985.37(04), 731-735.

[14]. Li, J., Mehta, S. A., Moore, R. G., Ursenbach, M. G., Zalewski, E., Ferguson, H., \& Okazawa, N. E. Oxidation and ignition behaviour of saturated hydrocarbon samples with 
crude oils using TG/DTG and DTA thermal analysis techniques. Journal of Canadian Petroleum Technology, 2004.43(07).

[15]. Jia, H., Zhao, J. Z., Pu, W. F., Liao, R., \& Wang, L. L. The influence of clay minerals types on the oxidation thermokinetics of crude oil. Energy Sources, Part A: Recovery, Utilization, and Environmental Effects, 2012.34(10), 877-886.

[16]. Li, Y. B., Cheng-Yuan, D., Pu, W. F., Jin, F. Y., Chen, Y. F., Li, D., \& Zhao, J. Z. The Influence of Pressure on the Low Temperature Oxidation (LTO) of Heavy Oil during the High Pressure Air Injection (HPAI) Process in Tahe Oilfield. In SPE Middle East Oil \& Gas Show and Conference. Society of Petroleum Engineers. 2015.

[17]. Huang, S., Jia, H., \& Sheng, J. J. Research on oxidation kinetics of tight oil from Wolfcamp field. Petroleum Science and Technology, 2016.34(10), 903-910.

[18]. Huang, S., Jia, H., \& Sheng, J. J. Effect of shale core on combustion reactions of tight oil from Wolfcamp reservoir. Petroleum Science and Technology, 2016.34(13), 1172-1179.

[19]. Liu, P. G., Pu, W. F., \& Ni, J. H. Catalytic effect analysis of clay minerals on lowtemperature oxidation of crude oil through combined thermal analysis methods. Petroleum Science and Technology, 2016.34(4), 343-349.

[20]. Al-Saffar, H. B., Hasanin, H., Price, D., \& Hughes, R. Oxidation reactions of a light crude oil and its SARA fractions in consolidated cores. Energy \& fuels, 2001.15(1), 182-188.

[21]. Hou, S., Ren, S., Wang, W., Yu, H., Qian, G., Gu, H., \& Liu, B. Feasibility study of air injection for IOR in low permeability oil reservoirs of Xinjiang Oilfield China. In International Oil and Gas Conference and Exhibition in China. Society of Petroleum Engineers. 2010.

[22]. Juan, E. S., Sanchez, A., Del Monte, A., Moore, R. G., Mehta, S. A., \& Ursenbach, M. G. Laboratory Screening for Air Injection-Based IOR in Two Waterflooded Light Oil Reservoirs. Journal of Canadian Petroleum Technology, 2005.44(01).

[23]. Gutierrez, D., Moore, R. G., Ursenbach, M. G., \& Mehta, S. A. The ABCs of in-situcombustion simulations: from laboratory experiments to field scale. Journal of Canadian Petroleum Technology, 2012.51(04), 256-267.

[24]. Bhattacharya, S., Mallory, D. G., Moore, R. G., Ursenbach, M. G., Mehta, S. A., \& Belgrave, J. D. Investigation of Thermal Finger Print in Accelerating Rate Calorimetry for AirInjection Enhanced Oil Recovery Processes. In SPE Oil \& Gas India Conference and Exhibition. Society of Petroleum Engineers. 2015.

[25]. Khansari, Z., Kapadia, P., Mahinpey, N., \& Gates, I. D. A new reaction model for low temperature oxidation of heavy oil: Experiments and numerical modeling. Energy, 2014.64, 419-428.

[26]. Dechelette, B., Heugas, O., Quenault, G., Bothua, J., \& Christensen, J. R. Air injectionimproved determination of the reaction scheme with ramped temperature experiment and numerical simulation. Journal of Canadian Petroleum Technology, 2006.45(01).

[27]. Kök, M. V., Sztatisz, J., \& Pokol, G. High-pressure DSC applications on crude oil combustion. Energy \& fuels, 1997.11(6), 1137-1142. 
[28]. Kök, M. V., Hughes, R., \& Price, D. Combustion characteristics of crude oil-limestone mixtures. Journal of thermal analysis, 1997.49(2), 609-615.

[29]. Kok, M. V., \& Keskin, C. Comparative combustion kinetics for in situ combustion process. Thermochimica acta, 2001.369(1), 143-147.

[30]. Jia, H., Zhao, J. Z., Pu, W. F., Zhao, J., \& Kuang, X. Y. Thermal study on light crude oil for application of high-pressure air injection (HPAI) process by TG/DTG and DTA tests. Energy \& Fuels, 2012.26(3), 1575-1584.

[31]. Kök, M. V., \& Gul, K. G. Combustion characteristics and kinetic analysis of Turkish crude oils and their SARA fractions by DSC. Journal of thermal analysis and calorimetry, 2013.114(1), 269-275.

[32]. Kok, M. V., \& Gundogar, A. S. Effect of different clay concentrations on crude oil combustion kinetics by thermogravimetry. Journal of thermal analysis and calorimetry, 2010.99(3), 779-783.

[33]. Bagci, S., \& Kok, M. V. Combustion reaction kinetics studies of Turkish crude oils. Energy $\&$ fuels, 2004.18(5), 1472-1481.

[34]. Mothé, M. G., Carvalho, C. H., Sérvulo, E. F., \& Mothé, C. G. Kinetic study of heavy crude oils by thermal analysis. Journal of thermal analysis and calorimetry, 2013.111(1), 663-668.

[35]. Cinar, M., Hasçaki, B., Castanier, L. M., \& Kovscek, A. R. Predictability of crude oil in-situ combustion by the isoconversional kinetic approach. SPE Journal, 2011.16(03), 537-547.

[36]. Kozlowski, M. L., Punase, A., Nasr-El-Din, H. A., \& Hascakir, B. The Catalytic Effect of Clay on In-Situ Combustion Performance. In SPE Latin American and Caribbean Petroleum Engineering Conference. Society of Petroleum Engineers. 2015.

[37]. Dong, X., Liu, H., Sun, P., Zheng, J., \& Sun, R. Air-foam-injection process: an improved-oilrecovery technique for waterflooded light-oil reservoirs. SPE Reservoir Evaluation \& Engineering, 2012.15(04), 436-444.

[38]. Barkia, H., Belkbir, L., \& Jayaweera, S. A. A. Oxidation kinetics of timahdit and tarfaya moroccan oil shales. Journal of thermal analysis and calorimetry, 2003.71(1), 97-106.

[39]. Pu, W. F., Chen, Y. F., Jin, F. Y., Li, Y. B., Sun, L., Yuan, C. D., \& Li, D. The kinetic analysis of coke formation under differential air-oil ratio during high pressure air injection. Petroleum Science and Technology, 2015.33(5), 503-509.

[40]. Liu, P. G., Pu, W. F., Ni, J. H., Ma, X. P., Zhang, J., \& Liu, M. Thermal investigation on crude oil oxidation kinetics through TG/DTG and DTA tests. Petroleum Science and Technology, 2016.34(7), 685-692.

[41]. Pu, W. F., Liu, P. G., Li, Y. B., Jin, F. Y., \& Liu, Z. Z. Thermal characteristics and combustion kinetics analysis of heavy crude oil catalyzed by metallic additives. Industrial \& Engineering Chemistry Research, 2015.54(46), 11525-11533.

[42]. Yoshiki, K. S., \& Phillips, C. R. Kinetics of the thermo-oxidative and thermal cracking reactions of Athabasca bitumen. Fuel, 1985.64(11), 1591-1598. 
[43]. Li, J., Mehta, S. A., Moore, R. G., Zalewski, E., Ursenbach, M. G., \& Van Fraassen, K. Investigation of the oxidation behaviour of pure hydrocarbon components and crude oils utilizing PDSC thermal technique. Journal of Canadian Petroleum Technology, 2006.45(01).

[44]. Kapadia P, Gates I D, Mahinpey N, et al. Kinetic models for low temperature oxidation subranges based on reaction products. SPE Heavy Oil Conference-Canada. Society of Petroleum Engineers, 2013.

[45]. Nickle, S. K., Meyers, K. O., \& Nash, L. J. Shortcomings in the use of TGA/DSC techniques to evaluate in-situ combustion. In SPE Annual Technical Conference and Exhibition. Society of Petroleum Engineers. 1987.

[46]. Vossoughi, S., Willhite, G., El Shoubary, Y., \& Bartlett, G. Study of the clay effect on crude oil combustion by thermogravimetry and differential scanning calorimetry. Journal of thermal analysis, 1983.27(1), 17-36.

[47]. Kök, M. Effect of clay on crude oil combustion by thermal analysis techniques. Journal of thermal analysis and calorimetry, 2006.84(2), 361-366.

[48]. Kok, M. V. Clay concentration and heating rate effect on crude oil combustion by thermogravimetry. Fuel processing technology, 2012.96, 134-139.

[49]. Jia, H., Zhao, J. Z., Pu, W. F., Li, Y. M., Yuan, Z. T., \& Yuan, C. D. Laboratory investigation on the feasibility of light-oil autoignition for application of the high-pressure air injection (HPAI) process. Energy \& Fuels, 2012.26(9), 5638-5645.

[50]. Pu, W. F., Liu, P. G., Li, Y. B., Jin, F. Y., \& Liu, Z. Z. Thermal characteristics and combustion kinetics analysis of heavy crude oil catalyzed by metallic additives. Industrial \& Engineering Chemistry Research, 2015.54(46), 11525-11533.

[51]. Greaves, M., \& Bentaher, A. H. Exothermicity characteristics of Wolf Lake heavy oil, Athabasca tar sand and medium heavy Clair oil. In Canadian International Petroleum Conference. Petroleum Society of Canada. 2006.

[52]. Bousaid, I. S., \& Ramey Jr, H. J. Oxidation of crude oil in porous media. Society of Petroleum Engineers Journal, 1968.8(02), 137-148.

[53]. Okasha, T. M., Menouar, H. K., \& Abu-Khamsin, S. A. Oil recovery from tarmat reservoirs using hot water and solvent flooding. Journal of Canadian Petroleum technology, 1998.37(04).

[54]. Kök, M. Influence of reservoir rock composition on the combustion kinetics of crude oil. Journal of thermal analysis and calorimetry, 2009.97(2), 397-401.

[55]. Tingas, J. Numerical simulation of air injection processes in high pressure light \& medium oil reservoirs (Doctoral dissertation, University of Bath). 2000.

[56]. Montes, A. R., Gutierrez, D., Moore, R. G., Mehta, S. A., \& Ursenbach, M. G. Is highpressure air injection (HPAI) simply a flue-gas flood?. Journal of Canadian Petroleum Technology, 2010.49(02), 56-63. 